\title{
Life Cycle Assessment of Jointly Produced Solar Energy Materials: Challenges \& Best Practices
}

Michele L. Bustamante, Berlyn Hubler, Gabrielle Gaustad, Callie W. Babbitt

Golisano Institute for Sustainability, 190 Lomb Memorial Drive, Rochester Institute of

Technology, Rochester, NY 14623

Corresponding Author: Gabrielle Gaustad, gabrielle.gaustad@ rit.edu, +15854756089

\begin{abstract}
Life cycle assessment (LCA) offers valuable insights for solar firms, including identification of opportunities for potential cost reduction at energy and material usage hotspots and establishment of environmental performance advantages over competitors. However, many advanced solar photovoltaic (PV) technologies contain key functional materials that are challenging to assess with LCA because they are jointly produced as coproducts or byproducts. Joint production is inherently challenging to LCA because it introduces the methodological problem of allocation, or the need to distribute environmental impact among multiple products of a single process. Additionally, these materials suffer from increased risk of price volatility, which further confound allocation approaches. Using two case studies of jointly-produced PVrelevant raw materials, tellurium and terbium, the present work demonstrates some of the unique methodological challenges faced during LCA; namely, variation in results based upon choice of allocation method and parametric variability in allocation factor inputs. Results show that choice of allocation method leads to variation in cumulative energy demand (CED) by a factor of 6 for tellurium and a factor of 27 for terbium while choice of averaging period for time-dependent data (i.e. price), while nearly negligible for tellurium (1 - 3\% decrease), leads to variation in CED by $25 \%$ for terbium. Further, despite representing smaller contributions by mass to total joint process output, not all coproducts and byproducts are affected the same way by choice allocation method, i.e. tellurium CED was greater by mass allocation than economic, whereas the reverse was true for terbium. These findings inform best practices helpful for LCA practitioners to generate more robust environmental impact assessments and inform decision making with greater resolution.
\end{abstract}

Keywords: life cycle assessment; allocation; coproducts; byproducts; photovoltaics

\section{Introduction}

Life cycle assessment (LCA) is a powerful modeling framework for comprehensive evaluation of environmental impact for products. The tool considers everything from raw material extraction to generation of energy used during manufacturing and transportation all the through waste management at the end of the product's useful life. The degree of extensive systems modeling required to conduct LCA allows for generation of complex results with many potential uses. For instance, impacts can be disaggregated by life cycle stage or even by individual processes to identify energy and material usage "hotspots". This result can be used, in turn, to help to recognize opportunities for cost reduction through commensurate energy and/or material reductions in these production steps. Additionally, comparative LCA among competing 
technologies can generate results that establish environmental performance advantages, create product differentiation, and secure space in the target market for growth [1]. Further, LCAs can reveal primary energy consumption of the product or an input material [2]. This result can be compared with energy consumption of different recycling approaches to help motivate technological, infrastructural, and policy development [3]. Capturing these energy savings from recycling can also potentially help solar firms both reduce costs and strengthen "green" product differentiation claims, boosting competitiveness in a crowded market.

Regardless of how the results are used, they must be reliable, which requires practitioners to pursue robust modeling techniques, considering as much case-specific data, detail, and modeling finesse as is realistically possible. One key challenge regards modeling environmental impact for minor and specialty metals. Many such materials are key to the functionality of advanced solar devices. Several studies have focused on the threat of physical scarcity on availability of solar raw materials, such as tellurium and indium [4-10]. However, a less well studied aspect of supply threat is their joint production. Since these materials are often geologically less abundant, they may not form ore deposits that would allow direct mining. Instead, the most economical pathway to recovery of these materials is as coproducts or byproducts of major metal extraction and refining processes [8,11,12]. These forms of joint production are challenging to assess using LCA because the tool is inherently product-focused. Therefore, when evaluating a shared process, the environmental impacts must be distributed among the multiple outputs of each process in some way. This situation is sometimes referred to as "the allocation problem," (e.g. Guinee, 2006 [13]). There is no universally acceptable method to conduct this impact partitioning, so it inevitably introduces a degree of variability through practitioner judgement about methodology and associated data selection [14].

The goal of the present work is to propose potential solutions to key methodological and data-driven variabilities in LCA of jointly produced metals, with a special focus on solar-relevant materials. The discussion begins with a thorough review of joint production processes and their challenges in the real world as well as in LCA; namely, need for allocation, choice of allocation method, and parametric variability in time sensitive allocation data (section 2 ). Then, the impact of these inevitable allocation decisions on LCA results is demonstrated using two case study models for joint product materials critical to advanced solar technologies: tellurium (Te) and terbium ( $\mathrm{Tb}$ ) used in cadmium telluride (CdTe) thin film PV and next generation spectral conversion cells, respectively (section 3). Finally, the authors share insights gained from conducting these case studies and recommend best practices to address the identified challenges in LCA of similar material systems (section 4). These insights are intended to guide LCA practitioners to improve reliability of results that may inform decision-making relevant to solar devices and far beyond.

\section{Joint Production Challenges}

Theoretically, there are two basic forms of mineral production: monoproduction and joint production. Monoproduction refers to an ideal production pathway where mineral ore is extracted, processed, and refined to yield a singular valuable product. Conversely, joint production refers to a compound production pathway where a shared mineral ore is extracted, and during processing and refining stages, multiple valuable products are generated. Coproduction is a form of joint production where the outputs are all similarly valuable. 
Byproduction is a form of joint production where there is a clear main product and one or more marginally valuable minor byproducts, usually scavenged from a waste stream $[15,16]$.

\subsection{Supply-Chain Challenges}

Monoproduction is the simplest form of production because it only has to be optimized for one material product. All costs incurred are attributed to the single final material, and therefore all extraction decisions are driven by profit maximization for that material. Despite being the simplest economically, monoproduction is a fairly uncommon route in reality; it is far more typical to produce multiple valuable products from a single mining process [12]. Particularly for materials that are geochemically rare or dispersed, it is economically advantageous to exploit residues generated throughout the purification processes of major metal production for their trace valuable content. This type of process is often generally referred to as coproduction; however, to avoid confusion with a distinct subcategory of this form by the same name, the general process will be referred to instead as joint production throughout the present work.

Joint production results in generation of a main product, coproducts, and/or byproducts. In certain situations there is a clear main product, which dominates in terms of mass and typically profit generation. There may also be coproducts, which contribute appreciably enough to the economics of the process that they are factored into profit maximization decisions. The coproduct(s) can sometimes justify the extraction process on its/their own; however, the ability of a coproduct to bear the costs of the shared process is not a requirement to be considered a coproduct. Byproducts, however, earn their name because they can never bear the costs of the shared process and are only extracted along with production of the main product and/or coproducts. As a result, byproducts do not factor into the process economic decisions and can lead to troubling supply-chain behavior, such as short term supply disruptions and price volatility [15-17] (Fig 1).

Because they are not mined independently, supply of a joint product is somewhat constrained by economic considerations for the main product. The degree of constraint is different for coproducts and byproducts. Since byproducts do not contribute meaningfully to profit, market forces such as greater demand or higher prices do not affect decisions to process more or less shared ore. This constrains the supply of the byproduct in a manner not directly related to its own demand, which can result in greater than average price volatility for byproduct materials [16]. It can also create scenarios where supply is temporarily disrupted due to demand growth in the face of unresponsive supply [11]. Conversely, coproducts are not as constrained because they do factor into process economic decisions [15-17]. However, they are more constrained than ideal monoproducts would be because the quantity supplied of each coproduct is selected to optimize the overall profit, not necessarily to respond optimally to market forces for any individual product. This results in the same effects as were observed for byproducts, but to a lesser degree.

Examples of solar materials that fit these criteria are plentiful. Gallium and indium, used in CIGS thin film PV and various III-V multijunction concentrator cells, are byproducts of aluminum and zinc production processes, respectively. Cadmium and tellurium, used in CdTe thin film PV, are both byproducts; of zinc and copper production respectively. Selenium, used mainly in CIGS PV, is also a byproduct of copper production [8]. By contrast, cerium, the most abundant of the jointly produced rare earth elements, which was previously used as a solar glass 
additive to prevent adhesive degradation [18], is often considered a coproduct. Further, polysilicon which is produced from quartz is not quite a monoproduct but a main product, since the silica fumes produced during smelting are sometimes condensed and sold on the market [19].

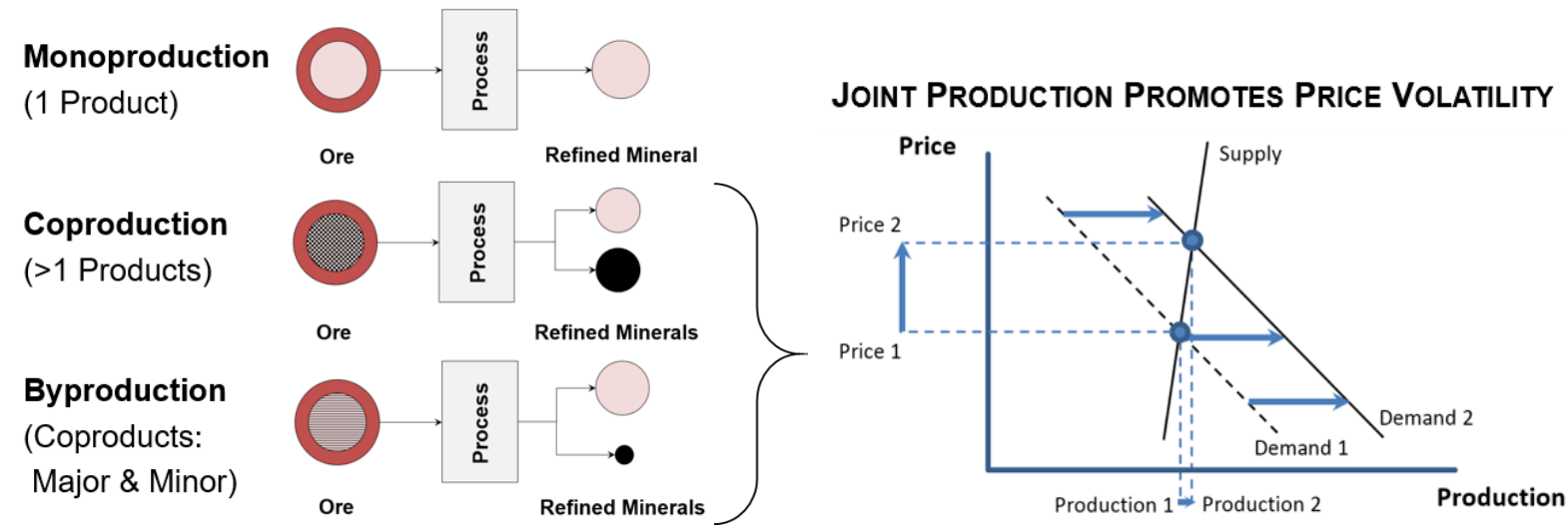

Fig 1. Forms of mineral production pathways, including joint production of coproducts and/or byproducts (left), and how joint production supply constraints can induce price volatility (right). Color of ore is used to indicate ore grade, i.e., darker gray for higher ore grade of minor joint product (black circles).

\subsection{LCA Challenges}

Joint production is inherently challenging for LCA because the modeling framework dictates that the environmental impacts of processes must be attributed to individual products. The International Standards Organization (ISO) has developed a procedure to guide practitioners facing this challenge and to encourage uniformity across studies [20]; however, their guidelines are not prescriptive and, as a result, leave a great deal of choice to the practitioner. This is problematic because it is well established that allocation choices can dramatically affect results [21-25].

The ISO guidelines for dealing with multi-output processes first recommends avoiding allocation of impacts, if possible [20]. Common methods for avoiding allocation include system expansion and system subdivision [26,27]. System expansion identifies a substitute process for producing the coproduct and compares it to the joint process, either claiming a credit for avoided production or adding it to the system to provide the second function via an alternate pathway. However, many joint products of multifunctional processes are minor coproducts or byproducts that are never produced independently; therefore, any alternate production processes also face the allocation problem, shifting rather than solving it. Allocation can also be avoided in some scenarios though more detailed process modeling, known as process subdivision. Subdivision involves further separation, where possible, to isolate subprocesses that lead directly to the production of the individual joint products. Again, this is often not possible because the joint products are separated during a single process step, i.e. anode slime created during electrolytic refining of copper or generation of flue gases during smelting.

When allocation avoidance is not possible, ISO dictates allocation based upon "physical causal" relationships, where possible [20,28]. In other words, impact should be partitioned based upon the degree to which each product drives the process. Distinction should be made to 
identify joint production processes where the secondary product is produced at a rate dependent or independent of the major product, where the former is considered causal. If a physical relationship cannot be established, any other relationship can then be used. As a result, there is still considerable debate within the LCA community as to which allocation method is most appropriate to use, if any, and under what circumstances [14,26,27,29]. The two most commonly used allocation methods are governed by tradition: mass-based allocation and economic (or market value-based) allocation. Mass allocation distributes impact to each product according to its share of total output on a mass basis whereas economic allocation distributes impact based upon share of total revenue generating potential. Mathematically these are represented as shown below:

Mass Allocation:

Economic Allocation:
$A F_{m, i}=X_{i} / \sum_{i} X_{i}$

where $\mathrm{AF}_{\mathrm{m}, \mathrm{i}}=$ mass allocation factor for product $\mathrm{i}$ with mass output $\mathrm{X}_{\mathrm{i}}$ $A F_{e, i}=P_{i} X_{i} / \sum_{i} P_{i} X_{i}$

where $\mathrm{AF}_{\mathrm{e}, \mathrm{i}}=$ economic allocation factor for product $\mathrm{i}$ with mass output $\mathrm{X}_{\mathrm{i}}$ and market price $\mathrm{P}_{\mathrm{i}}$.

In LCAs of metals and mining, economic allocation has unofficially been established as the allocation method of choice [30-32]. This trend has been justified by the idea that profit seeking behavior drives joint mining processes and therefore economic factors are fair bases upon which to partition impact. Further, it has been asserted that economic allocation is justifiable when the volume of the joint process actually varies in proportion to changes in the revenue contributions from the different products and that this is typically the case when no alternative production route or substitutes for the metal exist [33]. However, revenue-based allocation may not be appropriate for all joint production scenarios because it neglects cost considerations that factor into profit-driven decision making, such as increasing production volume, which are distinct for byproducts and coproducts.

Coproducts have the ability to bear costs of processing and byproducts do not [16]. In the absence of cost data, it may be impossible to definitively classify a joint product being modeled in LCA as a coproduct or a byproduct. Therefore, other forms of allocation need to be considered as well. For instance, allocation on the basis of physical relationships may be more appropriate for byproducts. When the minor product is scavenged from a waste stream, as is the case for tellurium recovered from copper refinery anode slime, there is no way to vary the output of the byproduct-containing stream (e.g. copper anode slime) except to process more main product (e.g. refine more copper concentrates), which would create a large oversupply of the main product (e.g. copper cathode) and cause the refiner to incur costs unjustifiable by the marginally profitable sale of byproduct (e.g. anode slime) to further processing facilities, meaning realistically it would not happen regardless of price.

Another obstacle that prevents variation in joint process volume in byproduction systems is the fact that there are typically multiple stakeholders along the supply-chain. Perhaps if one stakeholder managed the entire process from joint ore extraction to byproduct metal refining, it could be considered justifiable to extract more ore just to produce more byproduct; however, it is highly unlikely and contrary to the economic definition of a byproduct $[15,16]$. The economic justification is highly dependent upon the relative masses of the joint products, which can vary 
by several orders of magnitude (i.e. $~ 2.5$ grams of anode slime containing 20 - 80 milligrams of tellurium are yielded per kilogram of copper cathode refined [30]). In these cases, where the byproduct is so minor in mass that even very large changes in price of the byproduct are not enough to justify additional processing, using economic allocation would unfairly penalize byproducts (albeit by a small amount) when their production is more of a function of mass ratios. In reality, each process step is managed by a different stakeholder to their best benefit; extending the tellurium example, the copper miner is different than the copper refiner who is different than the anode slime processor and tellurium refiner. Each upstream actor acting in his own best interest economically sets a physical limit to the amount of tellurium being made available downstream. The copper miner's profit maximization is irrespective of the ore's tellurium content. Therefore, even if the optimal extraction of copper ore does not provide enough tellurium to meet demand, driving prices up wildly, it would not factor into the copper miner's decision on process volumes. It also would not likely factor into the copper refiner's decision to process more or less copper concentrates since its primary purpose is to produce copper and anode slime is just an unavoidable but marginally valuable output of that process. The only time the byproduct metal's value likely factors in would be in the further processing steps where tellurium-containing compound, copper telluride, has characteristics more like a coproduct. For other joint materials supplied in a similar fashion, choice of allocation method cannot be blindly assumed to be compatible with the industry-standard economic approach; however, as emphasized early, in absence of definitive classification, it should still be considered because it may apply under certain conditions.

When using the traditional economic allocation approach, impact determination can be further complicated by the prevalence of commodity price volatility. Significant changes in price of joint products over time can create variability in results by attributing the burden differently to each coproduct depending upon the time period selected. Many studies use average prices to address this issue [24,30,32]; however, the choice of averaging period is also subjective. A few studies have touched on this topic [24,32], but they did not consider how choice of distinct averaging periods could challenge results, not surprisingly understating the potential impact of this factor. Further, dramatic shifts in price over time can cause a joint product to be considered a coproduct instead of a byproduct or vice versa, making choice of appropriate allocation method a time-specific decision as well.

\section{Case Studies}

In the present work, LCA modeling will be applied to two distinct case study materials to illustrate the previously discussed challenges of evaluating environmental impact for joint product materials that are important to emerging solar technologies. The first case study is tellurium, used in CdTe PV. Tellurium is a byproduct of copper refining, and it represents a currently relevant solar material with strong modeling challenges not currently captured by existing database processes. The second case study is terbium; one of many rare earth elements to be used as phosphors in emerging designs for spectral conversion solar cells. Terbium is a minor rare earth element (REE), coproduced together with its fellow REEs from iron-bastnasite ore. Like many other phosphor candidate REEs, terbium is not currently modeled by existing LCA databases. Analysis of these two case study material systems represents two relevant and related systems with distinct challenges. 
These materials are also interesting because they are frequently targeted as potentially critical materials for their low abundance, high and volatile prices, dependence on joint production, and negligible recycling rates [34-36]. Critical materials are economically important materials with supply chain risk from industrial, economic, geopolitical, social, and/or environmental factors of production. For tellurium, many criticality studies have found it to be near-critical, especially in the short-term for the clean energy sector. Some recent studies even suggest that previous assessments may underestimate future supply risks for Te due to inadequate analysis of trends in use of copper production techniques which do not yield a tellurium byproduct [11]. In the case of terbium, as a rare earth element (REE), it has been frequently classified as critical [36,37], partially because global supply of terbium and the other REEs is highly concentrated. As of 2014, about $86 \%$ of all REE mining occurred in China [38].

For consistency and comparability, the two case studies apply as much common methodology as possible; however, they have key differences that require specific modifications as well. As such, a common methods section (3.1) will precede the presentation of the casespecific methods and results for each material (sections 3.2 and 3.3).

\subsection{Common methods}

LCA involves four general steps: goal and scope definition, life cycle inventory, life cycle impact assessment, and interpretation. Goal and scope definition establishes several important aspects of an LCA. First, it requires clear declaration of the purpose for the assessment; i.e., what will be done with the results. Next, it explicitly defines the system to be studied, including boundaries (both physical and temporal), processes, and flows that will and will not be modeled and justification for these decisions. Ideally, by the end of goal and scope definition it should be clear to the modeler what data needs to be collected to accomplish those goals. This data collection is accomplished during the next step, life cycle inventory. In the life cycle inventory, it should be clear what assumptions are being made about the data and respective modeling choices. Once all the lifecycle data have been inventoried, the environmental impacts are assessed for all the reference flows defined in the previous two steps. Life cycle impact assessment requires selection of an impact assessment method to translate reference flows of material and energy into environmental impacts determined to be relevant as defined in the goal and scope. The final step, which is really utilized all along the way, is interpretation. This means interpretation of results to glean implications for addressing the goals of the model as well as interpretation of modeling at each step in the process. This methodology may sound linear, but, in reality, interpretation is continually important to determine whether previous steps need to be revised in the face of modeling limitations [39].

\section{$\underline{\text { 3.1.1. Goal and scope definition }}$}

The goals of the case study LCAs are to improve current life cycle inventories, illustrate common challenges in modeling impacts of jointly produced solar raw materials, and demonstrate ways to potentially deal with these challenges. These goals are accomplished by performing globally representative cradle-to-gate LCAs for the two case study material systems, using a functional unit of $1 \mathrm{~kg}$ final material, where environmental impact is assessed for different allocation scenarios, time, and data assumptions. Temporal scope is limited to $2006-$ 2014 to encompass two averaging periods: 2006 - 2010, which has been used in a study where 
both case study materials are evaluated [32], and 2010 - 2014, which represents the most recently available data and a 5 year averaging period. The scenarios demonstrate the importance of these decisions on LCA results and implications for further decision making. System boundary diagrams for both case study LCAs are represented in Figure 2.

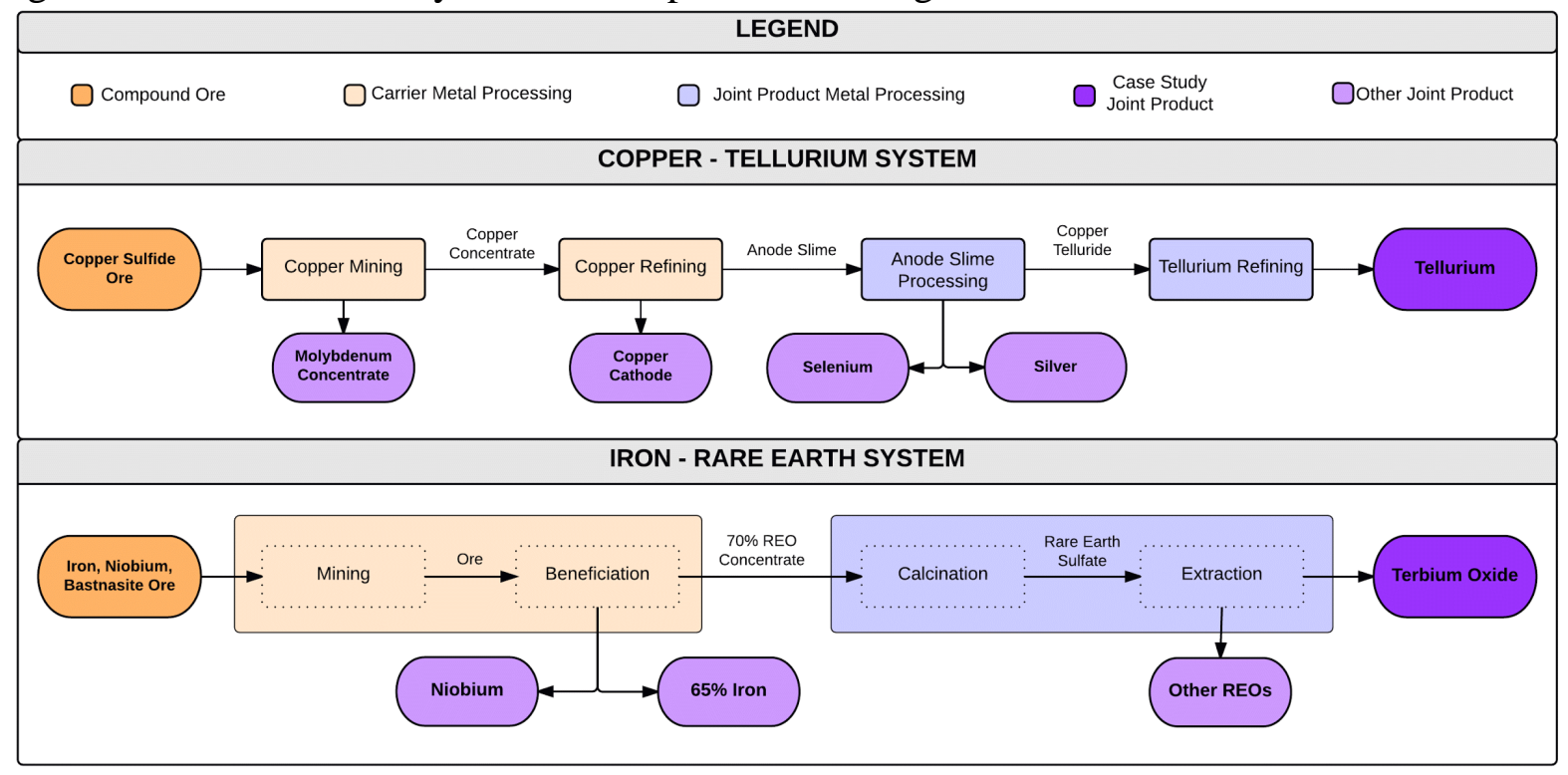

Fig 2. System diagram showing modeled processes and valuable outputs for the two case study LCA material systems: tellurium from copper ore (top) and terbium oxide from iron-rare earth ore (bottom).

\subsubsection{Allocation methods}

To probe variation in LCA results introduced by allocation assumptions, a host of allocation scenarios are created and applied to the two case study systems. These scenarios, summarized in Table 1, use different allocation methods and temporal scope assumptions. To facilitate comparison, a baseline scenario is selected against which all other scenarios will be measured. Economic allocation is used for this baseline scenario to be consistent with most mining or metal production LCAs. To represent a state-of-the-science model, the most recent inflation-adjusted 5-year averaging period of 2010-2014 is used to determine allocation factors. Additionally, to represent a situation where more recent time period data is not available, a distinct averaging period scenario is created which utilizes inflation-adjusted 2006-2010 data. Next, to represent a situation where a practitioner might not have access to historical data to create averages, new allocation scenarios are also created using data from individual years between 2006 and 2014, covering the whole time-frame of the study. Finally, to test the effects of alternate allocation method decisions, the second most common approach, mass allocation, is also generated for comparison for each time period assumed.

\section{$\underline{\text { 3.1.3. Life cycle inventory }}$}

Simapro 8.0 LCA modeling software is used to conduct the LCA case studies in line with ISO guidelines [20]. Raw, unallocated unit processes from ecoinvent (v. 3.01 available online) are used as a starting point to create custom process blocks in the software, updating data where 
available to reflect best knowledge of the case study material production systems [40]. Crucial case study specific modeling improvements are detailed in subsections 3.2.3 and 3.3.3. Allocation factors for each process were assigned according to methods described in the previous section 3.1.2 and case study specific sections 3.2.2 and 3.3.2.

\section{Table 1}

Summary of LCA scenarios considered. Each scenario is constructed using different allocation $\&$ time-related data assumptions.

\begin{tabular}{|l|l|l|l|}
\hline $\begin{array}{l}\text { Scenario } \\
\text { Code }\end{array}$ & Scenario Description & \multicolumn{1}{c|}{$\begin{array}{c}\text { Allocation } \\
\text { Method }\end{array}$} \\
\hline ECON_base & $\begin{array}{l}\text { Baseline scenario: } \\
\text { Economic allocation using averaging over most recent 5 year time period } \\
\text { for time sensitive data, mainly prices }\end{array}$ & economic & $2010-2014$ \\
\hline ECON_alt & $\begin{array}{l}\text { Alternate economic allocation using averaging over different 5 year time } \\
\text { period for time sensitive data, mainly prices }\end{array}$ & economic & $2006-2010$ \\
\hline ECON_year & $\begin{array}{l}\text { Economic allocation using individual year specific values for time sensitive } \\
\text { data, mainly prices }\end{array}$ & economic & $\begin{array}{l}2006-2014 \\
\text { (individual years) }\end{array}$ \\
\hline MASS_base & $\begin{array}{l}\text { Mass allocation using averaging over most recent 5 year time period for } \\
\text { time sensitive data, where applicable, mainly production ratios }\end{array}$ & mass & $\begin{array}{l}\text { Te: } 2010-2014 \\
\text { Tb: not } \\
\text { applicable }\end{array}$ \\
\hline MASS_alt & $\begin{array}{l}\text { Mass allocation using averaging over different 5 year time period for time } \\
\text { sensitive data, mainly production ratios }\end{array}$ & $\begin{array}{l}\text { Te: } 2006-2010 \\
\text { mass } \text { not } \\
\text { applicable }\end{array}$ \\
\hline MASS_year & $\begin{array}{l}\text { Mass allocation using individual year specific values for time sensitive } \\
\text { data, where applicable, mainly production ratios }\end{array}$ & $\begin{array}{l}\text { Te: } 2006-2014 \\
\text { (individual years) } \\
\text { Tb: not } \\
\text { applicable }\end{array}$ \\
\hline
\end{tabular}

\section{$\underline{\text { 3.1.4. Life cycle impact assessment }}$}

Cumulative energy demand (CED) is the impact assessment method selected for the present analysis. CED is a common, single issue impact assessment method, which accounts for the net energy generation and consumption throughout the product's modeled life cycle [2]. This method is selected for multiple reasons. First, CED, also known as embodied energy or primary energy, is a useful input for several decision metrics of potential interest to solar professionals. These metrics include energy return on investment (EROI) - a measure of life cycle net energy generation; energy payback time (EPBT) - a form of breakeven analysis to determine time to lifecycle net energy balance; and energy savings of secondary materials as compared to primary materials - a means for motivating recycling. Further, CED offers a certain level of methodological simplicity. As a single issue impact assessment method, the focus remains on allocation sensitivities, which is aligned with the goal of the present LCAs. Finally, although it lacks the comprehensivity of a broad impact assessment method like ReCiPe or TRACI, CED has been shown to represent an effective proxy for other key environmental impact metrics, such as global warming potential (GWP), a measure of greenhouse gas (GHG) emissions [41].

\subsection{Current technology case study: Tellurium in CdTe PV}

Tellurium was selected as a case study material for its use in a currently important solar technology, cadmium telluride (CdTe) thin film PV, and for its complete dependence upon 
byproduct supply. Tellurium, in compound form with cadmium, forms an inherent semiconductor material with near ideal fit to the incoming solar spectrum at intrinsic bandgap energy of $1.5 \mathrm{eV}$ [42]. Currently, CdTe is the dominant form of thin film photovoltaic technology on the market with over $10 \mathrm{GW}$ installed worldwide [43]. CdTe offers several technical benefits. It performs better at high temperatures than crystalline silicon technology [44], utilizes much less active material overall as a thin film technology [7], and boasts the most cost-effective manufacturing process of any commercially available technology [43]. Additionally, CdTe has also been touted as the current leader in environmental performance among commercial solar cells with energy payback time of less than 1 year among its strongest claims [3,45-47]. These environmental claims having been evaluated using LCA; however, as described in the following subsections, certain important system attributes may have been overlooked by modeling in these previous studies. Further, there are diverging opinions about the risk presented by use of potentially toxic materials in CdTe PV. Toxicity-related research has primarily focused on risk of cadmium release [48-51] since it is a potentially fatal, known human carcinogen and kidney antagonist, among other effects, in elemental form [52]. Toxicity of elemental tellurium is significant in animal studies, but in human exposure, effects are minimal [53]. A few studies have also characterized CdTe toxicity, showing inhalation to produced acute lung toxicity mortality at high concentrations in rats and concluding that CdTe is likely to be as toxic as cadmium [54]. However, due to encapsulation, risks of cadmium or CdTe exposure are proclaimed to be low, even in the extreme instance of fire $[50,55]$.

The following case study will focus on tellurium, specifically, as a fundamental raw material input to cadmium telluride PV technology and how the key modeling improvements related to joint production affect results.

\subsubsection{Tellurium case study: System definition}

Tellurium typically is produced as a byproduct from copper refining ( $>90 \%$ of supply); remaining supply also comes from byproduction with other metals such as lead, zinc, and bismuth [38]. Direct mining of tellurium is possible from a few recently developed ore deposits [56], however, this route is not currently being utilized due to lack of demand. Therefore, the scope of the tellurium case study was limited to this primary production pathway: via extraction from a copper refining byproduct known as anode slime. System boundaries were drawn to encapsulate the investigation around the following four sequential processes: (1) copper mining from sulfide ore, (2) copper refining via electrolytic method, (3) anode slime processing to separate valuable components, and (4) tellurium refining to produce semiconductor-grade material. Along this production pathway, many instances of allocation are required because the first three unit processes generate coproducts without substitutable production pathways, preventing system expansion, and often without clear causal delineation, preventing subdivision.

\subsubsection{Tellurium case study: Allocation}

As shown in Table 1, all tellurium allocation scenarios are associated with a specific time period. Even the mass allocation scenarios for the tellurium case study utilize time-specific data because the anode slime processing unit process block was designed in accordance with ecoinvent [30] to reflect realistic output levels of coproducts that reconcile with actual observed supply. This approach utilizes global production ratios to adjust anode slime joint products in 
proportion to changing anode slime content and yield, preserving mass balance while capturing realistic trends in supply. For the baseline mass and economic scenarios, a time period of 2010 2014 is utilized for all time sensitive data. For the alternate mass and economic scenarios, a time period of 2006 - 2014 is utilized for all time sensitive data. Individual year economic and mass scenarios utilize data from the associated year only, with no averaging.

\subsubsection{Tellurium case study: Data analysis and life cycle inventory}

Several changes were made to model tellurium production to the best of present research abilities. First, the upstream copper extraction processes (orange blocks in Fig. 2 (top)) were connected to the downstream byproduct extraction processes (blue blocks in Fig. 2 (top)). The existing modeling in ecoinvent employed a cut-off approach, separating the copper refining block from the anode slime generation block when in reality they result from the same process. Next, copper refining was modified so that only copper refining processes resulting in tellurium production were included. This was accomplished by substituting all irrelevant copper inputs, such as copper mined by solvent-extraction (SX-EW), with copper mined as concentrates (1:1 $\mathrm{w} / \mathrm{w})$. Further, prices and production figures used in inventory calculations prescribed by ecoinvent [30] were updated as necessary.

Production data was obtained from USGS for all joint process outputs except copper and tellurium. This alternative sourcing was selected because USGS production figures did not describe the appropriate process for copper (mining reported versus refining) and were incomplete for tellurium (plagued by proprietary withholding). Recalling that only electrolytically refined copper yields tellurium-rich anode slime byproduct, use of total mining data reported in USGS overstates production ratio of copper to tellurium, which is used in certain inventory calculations as in Classen [30]. For tellurium production, many nations known to produce tellurium do not report their production figures, including the United States, and therefore an accurate global production estimate cannot be made from the reported data [38]. In lieu of reported tellurium data, the ICSG electrolytically refined copper production data was used as proxy for tellurium production according to methodology previously described [11].

Finally, an additional coproduct, selenium, was added to the anode slime processing step to more accurately reflect global coupled production. Each year, more selenium is available and ultimately produced from the same anode slime [57], making it inappropriate to exclude selenium from allocation considerations in an LCA of tellurium. The resulting reference flows and prices for each allocation scenario are shown in figure 3.

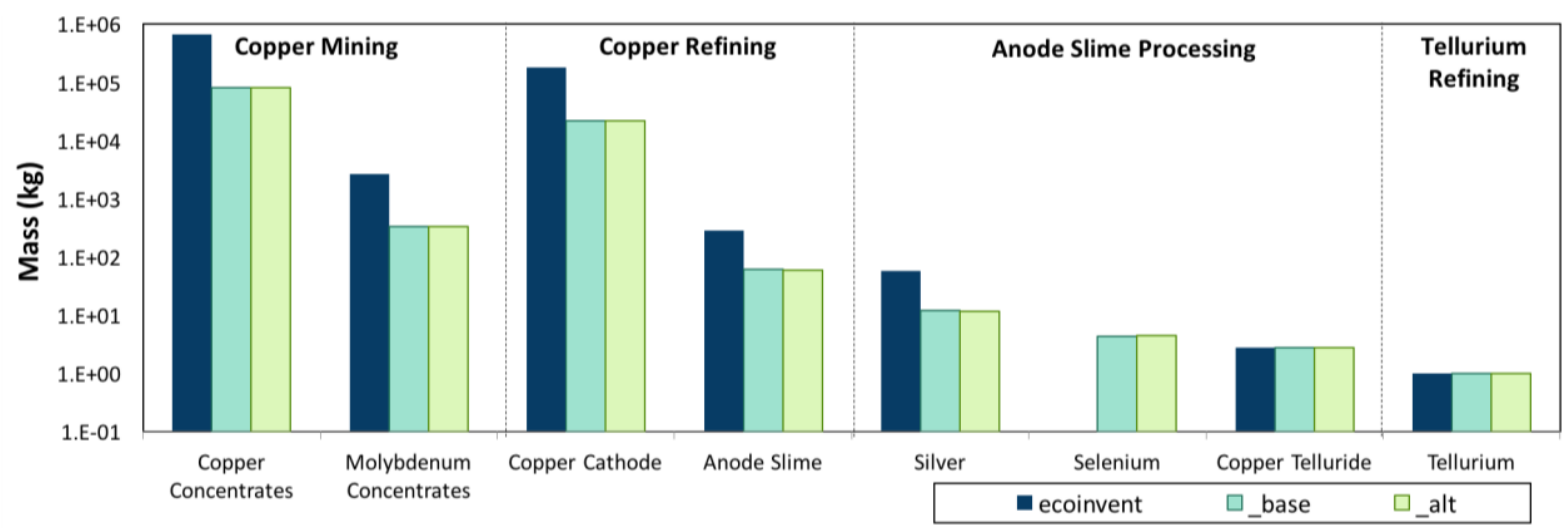




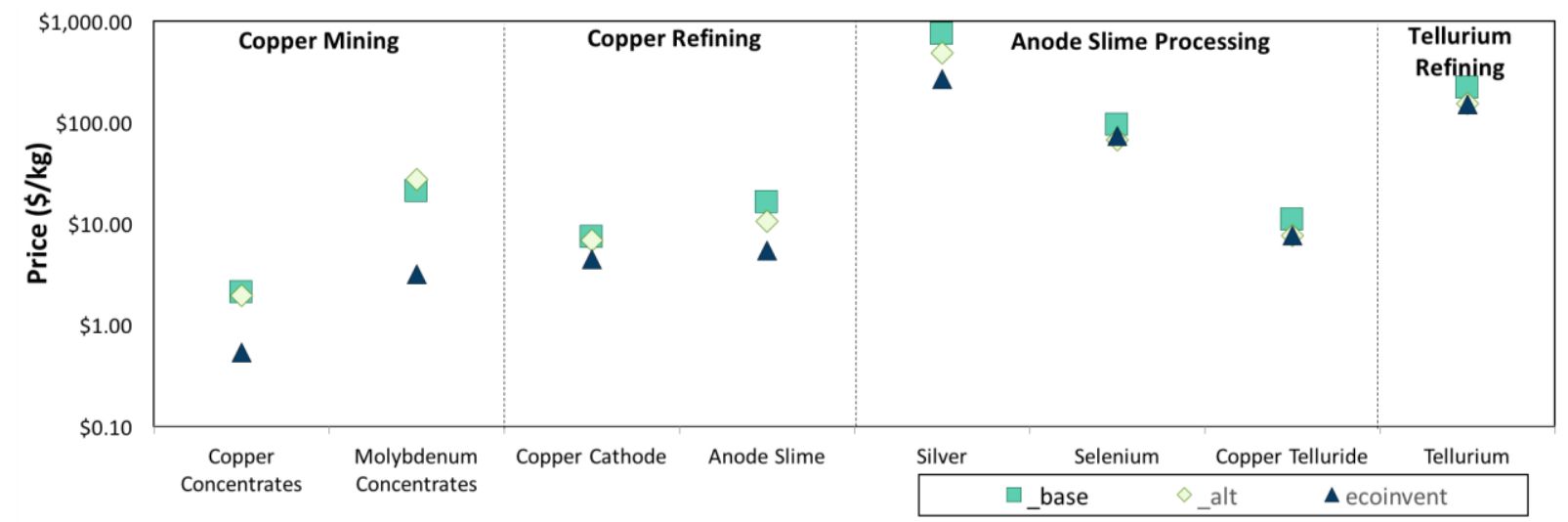

Fig 3. Tellurium case study: reference flows (top) and price data (bottom) assumed for tellurium case study. Flows vary between base and alt scenarios but are not visible on log scale.

\subsubsection{Tellurium case study: Results \& discussion}

CED results for the averaged time period scenarios are summarized in figure 4. The change in CED, relative to the base case, suggests the variation associated with two different aspects of allocation: 1) choice of method (e.g. mass versus reference case), and 2) price variation (i.e. recent versus prior 5 year timeframe). Both economic scenarios resulted in very similar CED, with only a $2 \%$ decrease observed when using the older timeframe. This result was surprising, since tellurium price varied by more than $50 \%$ in either direction over the course of the two considered time periods.

The greatest CED is obtained from allocation by mass, a near 6-fold increase in CED estimation over the base case economic scenario. This result is somewhat counterintuitive; since tellurium is a very minor coproduct in terms of mass but has a fairly high value compared to copper, it was expected that economic allocation would assign a greater impact to tellurium. However, since tellurium is extracted from the anode slime as a compound, CuTe, and it is coproduced along with silver and selenium during this process, the results depend upon the relative trends in price and production among the coproducts. Silver has a much higher price than $\mathrm{CuTe}$ (estimated based upon recoverable tellurium content) and also a higher output relative to tellurium in the reference case, skewing the economically-allocated impact away from tellurium. These finding highlights the importance of system perspective in modeling of complex production systems as well as the potentially powerful impact associated with allocation method selection. 


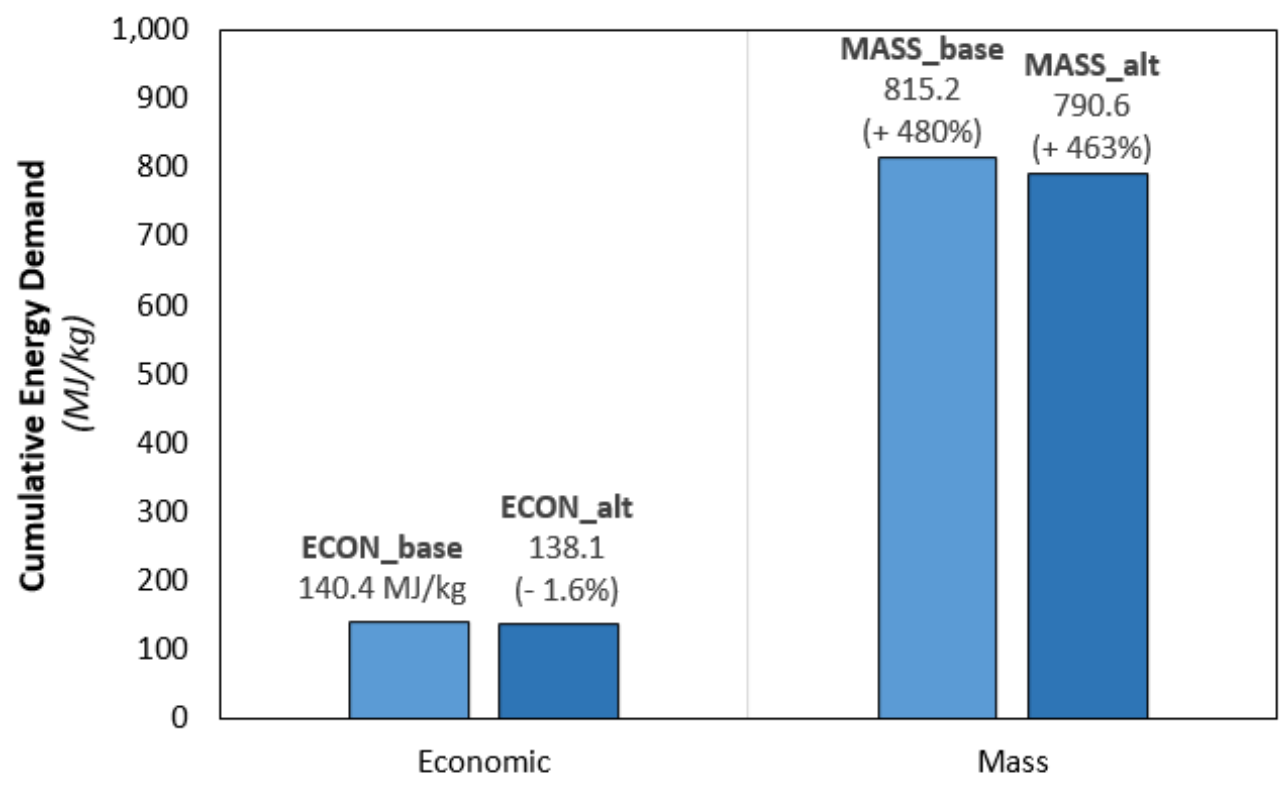

Allocation Method

Fig 4. Tellurium case study: cumulative energy demand results for each data-averaged allocation scenario.

Further analysis based on individual annual price and production values yields smaller variation than choice of allocation method. Under economic allocation assumption, results range from $11 \%$ above the reference case (2011 data) to $10 \%$ below (2007 data). This variation is not as large as might be expected from looking at tellurium price variation alone over the same time period. Pure tellurium price averaged $\$ 1998122$ from 2006 - 2014, peaking at $\$ 1998253(+107 \%)$ in 2011 to more than double the period average, and sinking to nearly half the average in 2007 at $\$_{1998} 67.50$ (-47\%) [58]. Conversely, under mass allocation, in which only the production ratios change, the year to year CED and energy savings deviations from average are much smaller. The maximum deviations in each direction are observed in $2007(-5.6 \%)$ and $2013(+1.4 \%)$. Using an averaging period of 2006 - 2010 instead of the baseline 2010 - 2014 for mass allocation resulted in a $3 \%$ reduction in expected CED, which is double that of economic, but still small. The larger difference between averaging periods suggests more recent trends in production data may skew results more than price trends or that price trends counteract some of the production trends. After all, economic allocation is simply a price weighted mass allocation. 


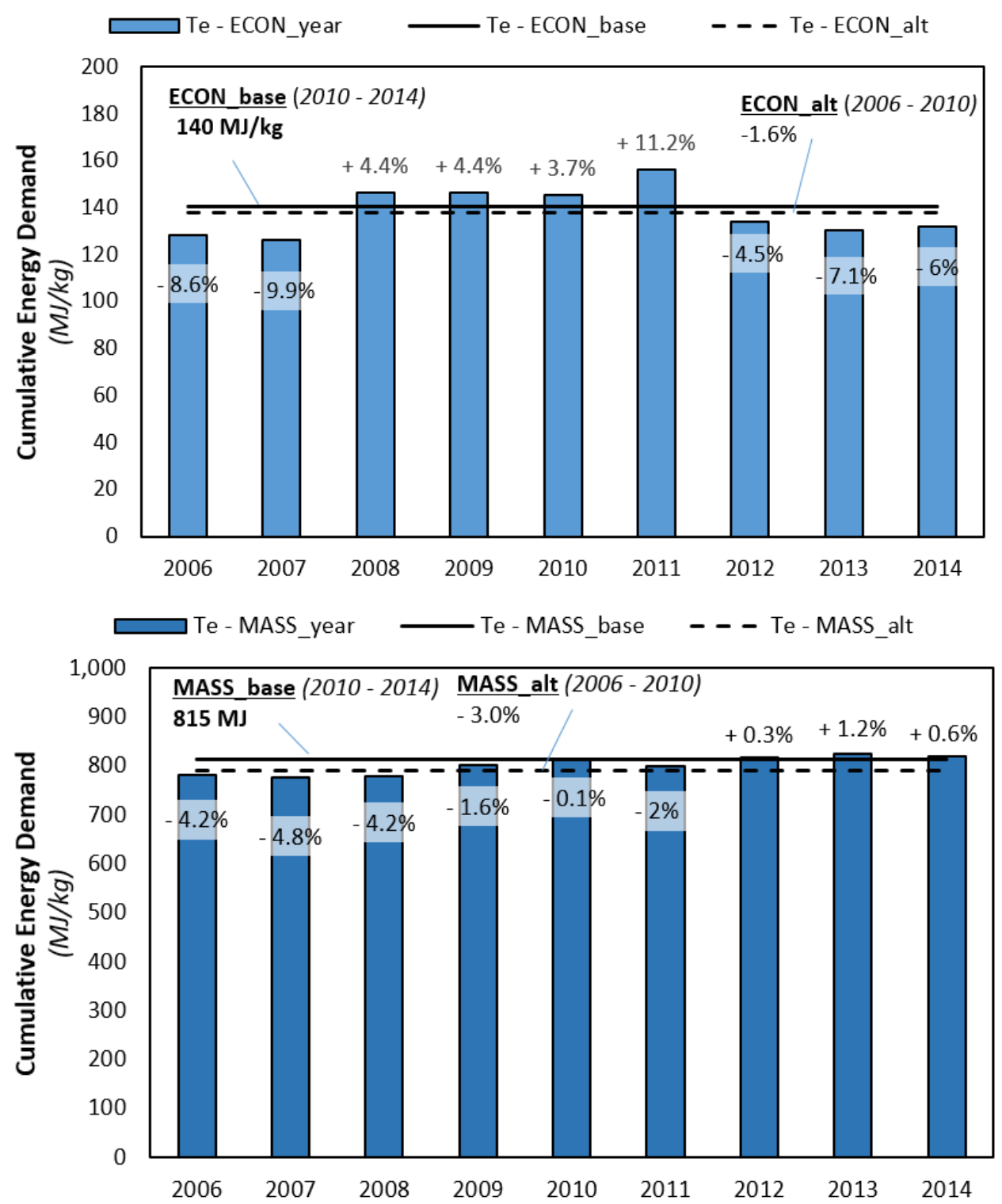

Fig 5. Tellurium case study: CED variation as a result of data period assumptions for single years from 2006 - 2014 (_year), average values for 2006 - 2010 (_base), and average values for 2010 - 2014 (_alt). Top: economic allocation scenarios. Bottom: mass allocation scenarios.

\subsection{Future technology case study: REEs in spectral (up/down) conversion PV}

Several of the rare earth elements have been considered for use in PV applications to shift more of the available solar spectrum into the usable range for the active semiconductor material using phosphorescence. In early studies it was noted that single use of rare earths was not ideal, but some combinations such as $\mathrm{Yb}^{3+}$ and either $\mathrm{Tm}^{3+}$ or $\mathrm{Tb}^{3+}$ could provide down conversion benefits, and later studies suggest that higher amounts and varied combinations can provide improvement [59-65]. Although several REE are considered for these applications, this study focuses on a single element, $\mathrm{Tb}$, for consistency with the Te case study. Although $\mathrm{Tb}$ is not the most commonly tested, it is considered a conservative case study, since others, such as Ho, Er, and $\mathrm{Yb}$, are found in such small quantities (trace) compared to $\mathrm{Tb}$ and other rare earths that may 
have even higher cumulative energy demand per kilogram functional unit.

\subsubsection{Terbium case study: System definition}

The scope of the terbium case study was bound to production from a single mine in China, known as Bayan Obo (>50\% of global supply) [66-68]. This mine produces iron, niobium, and rare earth oxides. System boundaries were drawn to investigate the following four processes: 1) mining iron ore, 2) beneficiation to produce iron, niobium, and REO concentrate, 3) calcination of rare earth concentrate, and 4) extraction of individual rare earth oxides. The four processes were modeled as two units reflecting the points where allocation occurs: 1) mining and beneficiation to produce iron, niobium, and REO concentrate, and 2) calcination and extraction to produce individual rare earth oxides. This study models an output of $1 \mathrm{~kg}$ REO and uses this as a proxy for individual REO production, though it is assumed the impacts for the individual production, if modeled, would be higher.

\subsubsection{Terbium case study: Allocation}

Price data deviates from ecoinvent's existing model because it is based on most recent data from the USGS [69,70] and other independent commodity price sources [71,72]; specifically ecoinvent uses 2002 for the Sm-Gd-Eu compound and 2004-2006 average for $\mathrm{Nd}$, $\mathrm{Pr}, \mathrm{La}$, and Ce [73]. For mass allocation, temporally-specific data is not available for individual rare earth production, so this aspect is not considered in its mass allocation calculations.

\subsubsection{Terbium case study: Data analysis and life cycle inventory}

There is no existing unit process for terbium production in ecoinvent, so a new one has been constructed by augmenting an existing rare earth oxide production module. The first major modification to the rare earth system was the inclusion of mining for iron ore from the joint production site in China. The existing modeling in ecoinvent utilizes a proxy for bastnasite ore based on REO compositions of Mountain Pass, CA and Bayan Obo, and consequently cuts off the production of iron and niobium products from the mining and beneficiation process that occurs at Bayan Obo [73]. As the existing ecoinvent model only yields five rare earth oxides (Ce, Pr, La, Nd, and a Sm-Eu-Gd mixture), outputs of the calcination and extraction process were expanded to include all rare earth elements produced from the mixed REO ore concentrate. The outputs were modified to reflect the composition of Bayan Obo bastnasite, as reported by USGS [74]. The product reference flows and price assumptions for this case study are shown in Fig. 6. 

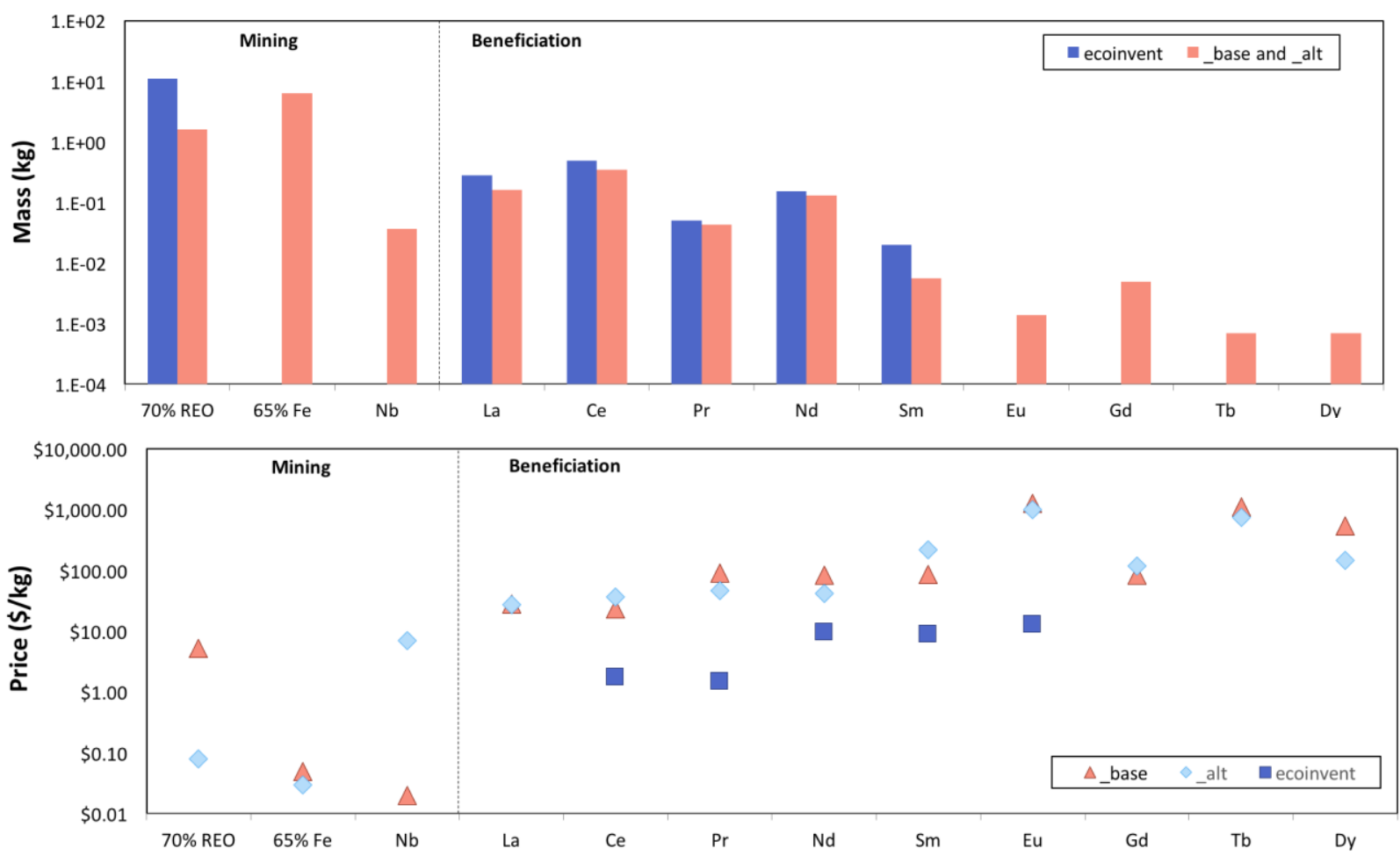

Fig 6. Terbium case study: reference flow (top) and price (bottom) assumptions for REE case study LCA. Note: _base and_alt scenarios have the same reference flows for this case study but different prices.

\subsubsection{Terbium case study: Results \& discussion}

LCA results for the terbium case study are presented in figure 7 . For the mass allocation, CED is $199 \mathrm{MJ} / \mathrm{kg}$. The highest CED result for all scenarios is for the year 2012 (7902 MJ), during which the highest prices for terbium oxide were observed $\left(\$_{1998} 1384.50 / \mathrm{kg}\right)$, second only to the prices for europium of all of the REOs produced. Using mass allocation instead of base economic allocation results in a $96 \%$ decrease in CED. The mass allocation factor alone is not as significant as the combination of mass fraction and market value, where terbium's market value is consistently the second highest among its coproducts. This difference is mainly due to the comparatively small production ratio for $\mathrm{Tb}(0.1 \%$ of total rare earth oxide), but high market value [74]. For the economic allocation scenarios, a $25 \%$ decrease in CED is observed by using the alternate time period of 2006-2010 market values over baseline 2010-2014 values. 


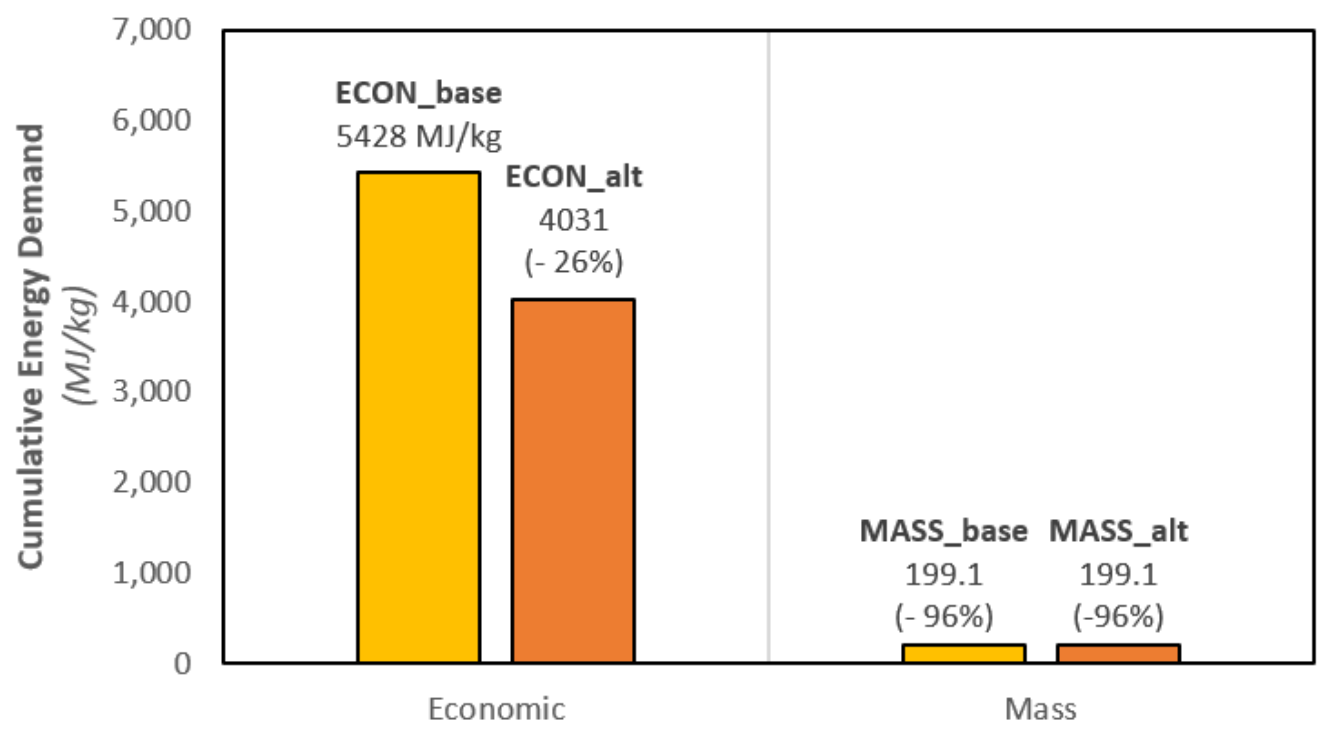

Allocation Method

Fig 7. Terbium case study: Cumulative energy demand results for each data-averaged allocation scenario in terbium case study.

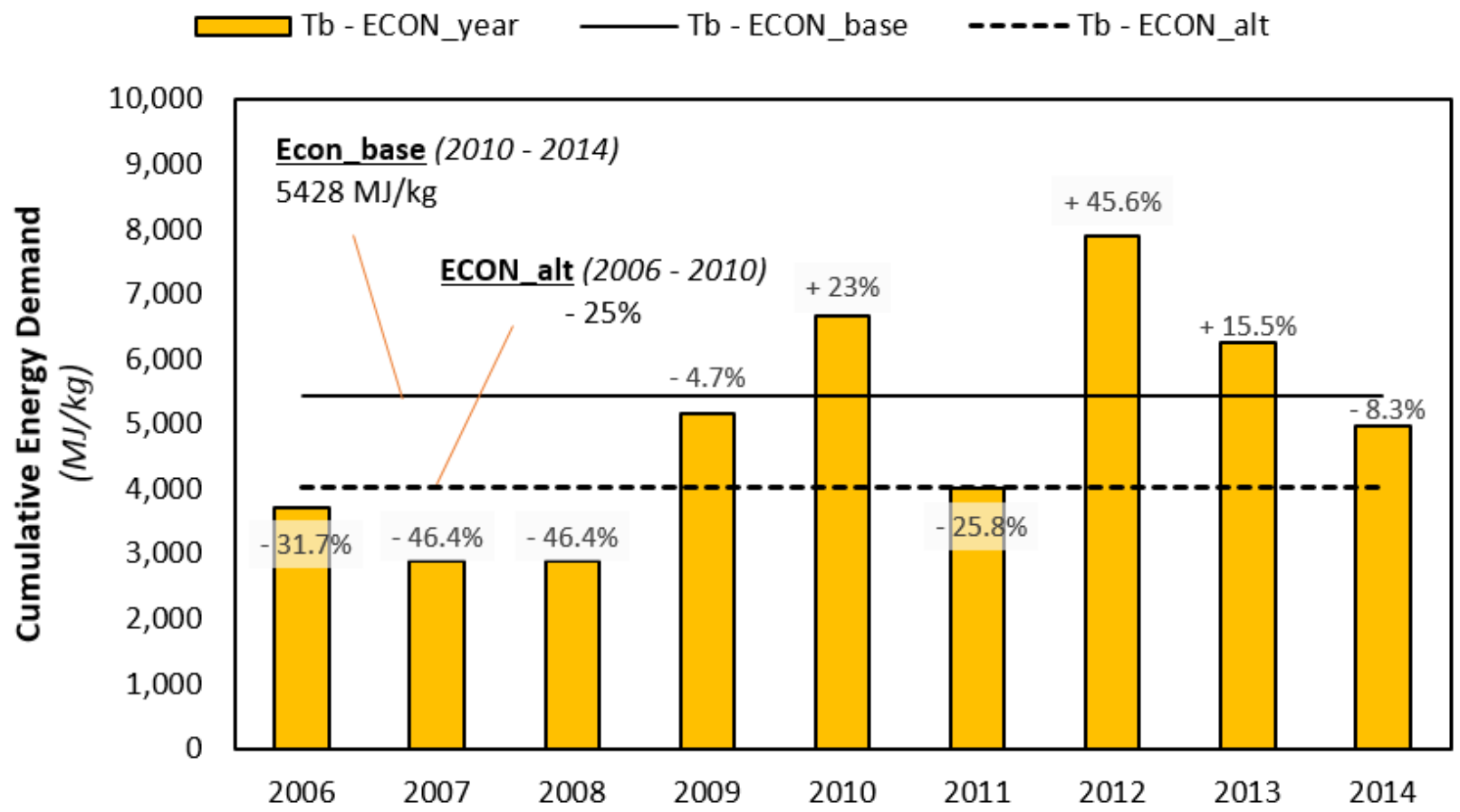

Fig 8. Terbium case study: CED variation as a result of data period assumptions for terbium case study: single years from 2006 - 2014 (ECON_year), average values for 2006 - 2010 (ECON_base), and average values for 2010 - 2014 (ECON_alt). Note: mass allocation scenario for this material are not modeled to be time dependent. 


\subsection{Cross-case study comparison}

Along with joint production, other similarities exist between the two systems. For both tellurium and terbium, existing models employ cut-off methods to avoid allocating impacts for joint production at the mine. This is concerning because, depending on the scope of the LCA and allocation method, upstream processes can contribute a significant amount to the overall impacts (e.g., Anctil et al. 2013). Both case studies also integrate updated allocation factors for the mass and economic scenarios; however, tellurium also includes temporal effects within its mass allocation via changing production ratios to reflect variation in anode slime content and yields over time. This information was not available for the rare earth/terbium case study, so the CED results for mass allocation are the same for both its baseline and alternate mass allocation scenarios. As a result, tellurium displayed temporal variation in CED by mass allocation for the individual years while terbium did not.

Although small (3\% decrease for MASS_alt), choice of averaging period affected mass based CED for tellurium more than it did for economic based CED (1.6\% decrease for ECON_alt). Compared to terbium, tellurium did not see much variation in the mass and economic temporal study, at most an $11.2 \%$ change from the baseline; terbium saw significant variation in its economic allocation with its smallest change at $4.7 \%$ below the baseline and its largest at $46 \%$ below. This difference between these two systems may stem from a greater skew in the dynamic price behavior for some of the REE joint products. Even using inflation-adjusted price values, the system exhibits huge price variation for some of its more minor outputs, like europium, terbium, and dysprosium, as compared to cerium, lanthanum, and neodymium (Fig 9) and the peak is heavily weighted toward the second averaging period (ECON_alt) creating a larger difference between the chosen averaging scenarios.

Additionally, despite displaying a smaller percent change value, the magnitude difference between economic and mass scenarios for terbium was larger than that of tellurium and represented a larger relative change; economic to mass CED ratio is 1 to 5.8 for tellurium but 27 to 1 for terbium. The most distinct difference discovered between the two case study systems was that, in the case of tellurium, the highest CED was realized for a mass allocation scenario; whereas in the case of terbium, the highest was an economic allocation scenario. The difference between the two systems stems from the economics of the upstream processing steps (Fig 9).

To understand, trace the tellurium-bearing joint products through each multi-output process; copper concentrate from copper mining, anode slime from copper refining, and copper telluride from anode slime processing. The tellurium-bearing output is typically the lowest priced among its coproducts; in the copper mining step, molybdenite is 6 - 18 times more valuable per unit $(\$ / \mathrm{kg})$ than copper concentrate, and, in the anode slime processing step, silver and selenium are 45 - 138 times more valuable than copper telluride is estimated to be. The exception is anode slime which has similar price per unit to copper cathode (only 1.2 to 2.7 times greater) but opposing rank in relative mass outflows (2.6 - 2.9 grams anode slime produced per kilogram copper cathode), creating a value difference between the products of 130 - 340 times greater for copper cathode as compared to the tellurium-bearing anode slime. Note that, in the case of copper telluride and anode slime, valuation was determined in line with Classen et al [30] methods, which assumed a value of the intermediate product (anode slime and copper telluride) that is $10 \%$ of the pure value of the contained metals (silver, selenium, and tellurium). Sensitivity of results to this kind of methodological assumption are not probed in the present 
study, but since they directly determine price, selection of a different valuation method may also strongly affect economic allocation results.

Tracing the terbium-bearing joint products is a simpler pursuit, since there are only two points of joint product: $70 \%$ REO concentrate from iron-bastnasite mining and beneficiation and terbium oxide from REO concentrate calcination and refining. In each instance, the opposite is observed; the terbium-bearing joint products are always the highest priced: the mixed REO concentrate is 43 - 181 times more valuable than the mixed iron ore and 96 - 442 times more valuable than the niobium with which it is produced, and terbium oxide is the second highest valued REO, ranging from 0.6 - 173 times the unit value of any of its coproducts.

Additionally, both the tellurium- and terbium-bearing joint products are typically the lower contributors to total process mass output (see Fig 3 \& Fig 6). Considering these mass flow trends in the context of the price trends throughout the joint production systems explains their behavior. Tellurium, as a component of the lower valued outputs and, in most cases, the lower magnitude flows, would display a smaller allocation factor using economic versus mass allocation. However, terbium, as a component of the highest valued outputs but lower magnitude flows, would display the opposite behavior with an allocation factor strengthened by economic methodology over mass. This difference highlights how the decision of allocation method might change the results differently for different systems, especially in the case of a comparative LCA. It also highlights that while both systems are subject to joint production, choosing to allocate based on industry norms may still yield mixed results.

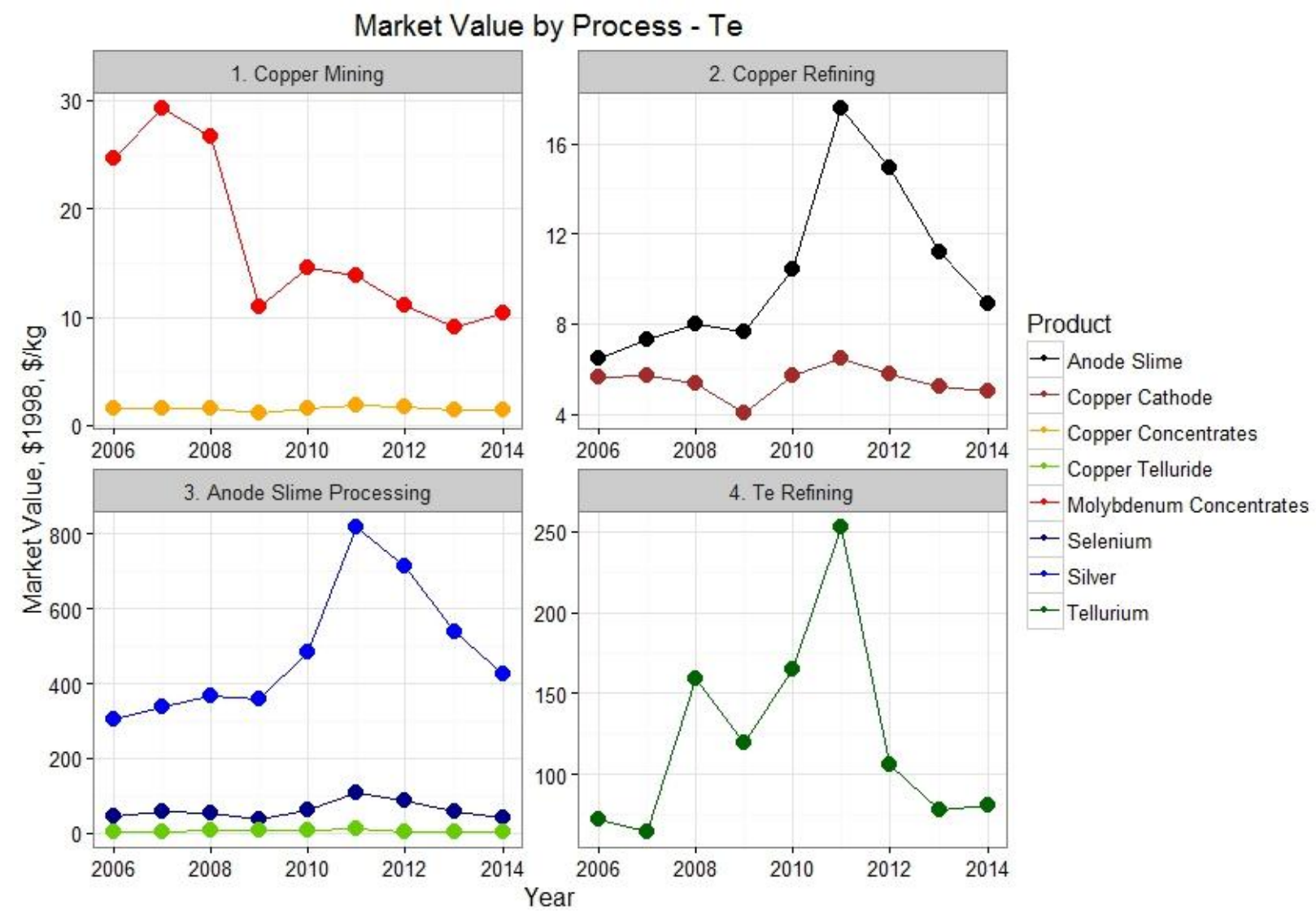




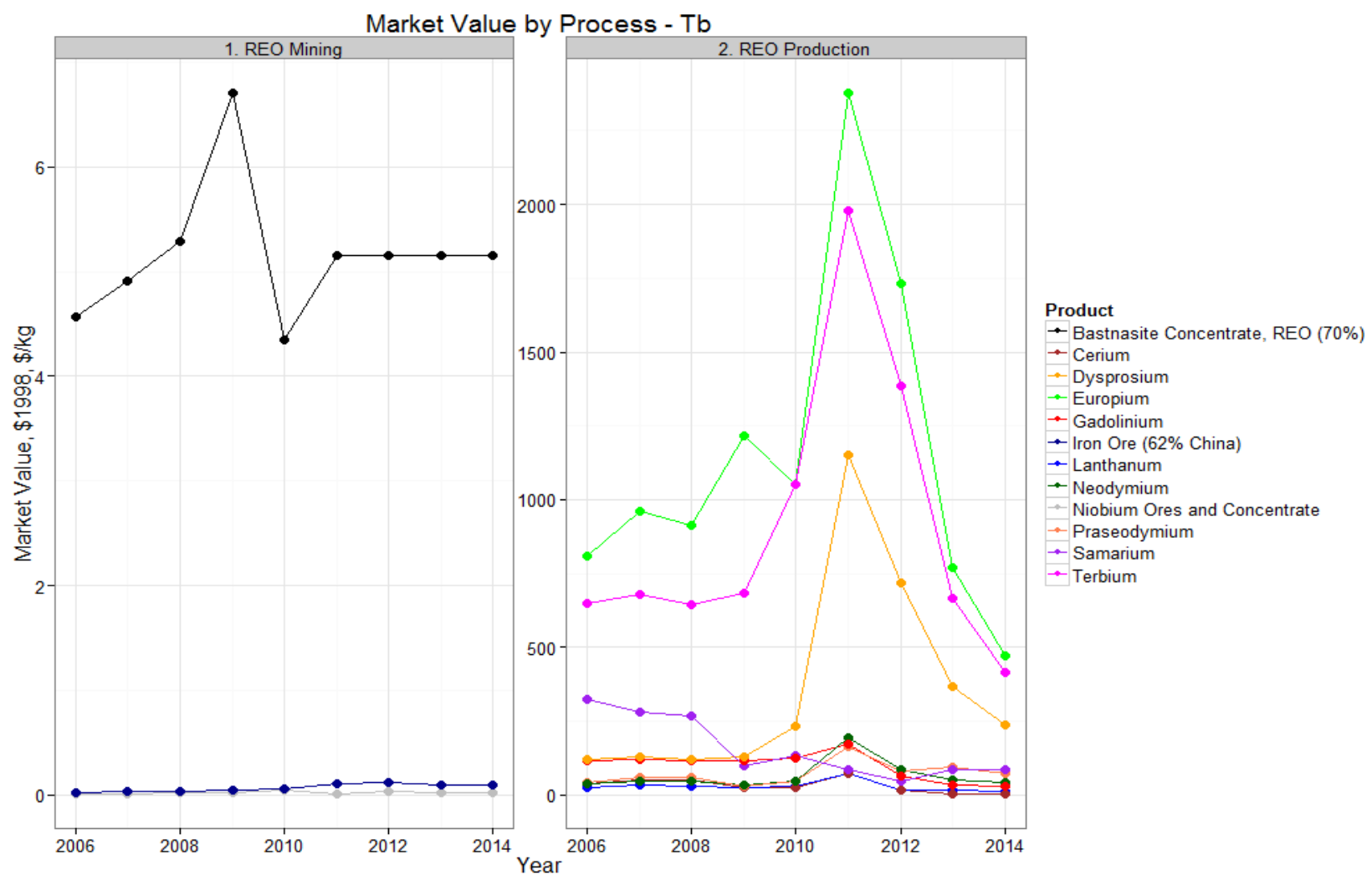

Fig 9. Unit price behavior for joint products of each unit process for (top) tellurium case study and (bottom) terbium case studies, demonstrating the importance of accounting for price volatility and system perspective in LCA of joint product materials.

\section{Best practice recommendations}

The findings from these case studies identify three common challenges for LCAs of solar materials: (1) existing LCI process data, if it exists, may not fully incorporate joint production; (2) choice of allocation method dramatically affects results; (3) temporal variation in allocation data can also strongly impact results, but only in the case of non-normally approximate data series. To address these challenges, several broad practices are recommended (Table 2) and described in greater detail in the following subsections. It is anticipated that these practices will contribute to the growing effort to standardize and improve solar LCA (e.g. International Energy Agency PV Power Systems (IEA PVPS) Methodology Guidelines on Life Cycle Assessment of Photovoltaic Electricity [75]).

Table 2. Summary of best practice recommendations for joint product solar cell materials.

\section{Challenges}

Joint production poorly modeled in existing LCI modules

Allocation method can dramatically change results

\section{Best Practices}

- Examine temporal and methodological assumptions of existing modules before using

- Connect upstream and downstream joint production process inputs

- Use multi-output processes to model joint production systems

- Substitute real process data wherever possible

- Selecting allocation methods to reflect causality when possible

- If not possible, report at least two methods with justification; no method is technically correct

- Use results from each method to provide bounds for expected results 
Time sensitive data assumptions can dramatically change results
- Use ranges during decision making to improve reliability

- Consider historic price volatility for coproducts

- If averaging, use inflation-adjusted values

- Where possible, provide bounded results from min and max values of time sensitive data

\subsection{Modifying existing LCI processes to account for joint production}

When evaluating environmental impact for a product or material, a common first step before conducting an entirely new and full LCA is to review the available literature and browse existing LCI databases for results. Theoretically, one could pull these published results directly or utilize the existing process blocks; however, this can be dangerous, particularly for joint product materials, without thorough consideration about the system modeling, allocation method, and allocation data assumptions. For example, in the case of the selected case study materials, there are several published LCAs (Table 3). For tellurium, only economic allocation values were found to have been reported. However, the time period assumptions for the price data or any other time sensitive modeling parameters are not always transparent. Those who do report have utilized different time period averages, e.g. 2004 - 2006 [30], 2006 - 2010 [32], 2008 - 2010 [56], and report results varying from $124-435 \mathrm{MJ} / \mathrm{kg}$ of tellurium and $199-8057 \mathrm{MJ} / \mathrm{kg}$ for terbium.

Table 3. CED results compared to results from other studies in the literature.

\begin{tabular}{|c|c|c|c|c|}
\hline \multirow[b]{2}{*}{ Source } & \multirow[b]{2}{*}{ Allocation Method } & \multirow[b]{2}{*}{ Temporal Scope } & \multicolumn{2}{|c|}{ Results CED (MJ/kg) } \\
\hline & & & Tellurium & Terbium \\
\hline ecoinvent $2.0[30]$ & Economic & $2004-2006^{*}$ & 124 & $\mathrm{~N} / \mathrm{A}$ \\
\hline ecoinvent 3.1 (Simapro 8.0.5) & Economic & $2012-2014$ & $* * 105-185$ & $\mathrm{~N} / \mathrm{A}$ \\
\hline Nuss \& Eckelman, 2014 [32] & Economic & $2006-2010$ & 435 & 7510 \\
\hline \multirow{2}{*}{ Zaimes et al., 2015 [76] } & Mass & N/A & N/A & 579 \\
\hline & Economic & 2011 & N/A & 8057 \\
\hline Goe \& Gaustad, 2014 [77] & Economic & $2010-2013$ & 157 & N/A \\
\hline Anctil \& Fthenakis, 2013 [56] & Economic & $2008-2010$ & 410 & N/A \\
\hline This study: ECON_base & Economic & $2010-2014$ & 140 & 5428 \\
\hline This study: ECON_alt & Economic & $2006-2010$ & 138 & 4031 \\
\hline This study: MASS_base & Mass & $\begin{array}{l}\text { Te: } 2010-2014 \\
\text { Tb: N/A }\end{array}$ & 815 & 199 \\
\hline This study: MASS_alt & Mass & $\begin{array}{l}\text { Te: } 2006 \text { - } 2010 \\
\text { Tb: N/A }\end{array}$ & 790 & 199 \\
\hline This study: $\mathbf{x} \_$year, extreme low & $\begin{array}{l}\text { Te: } \mathrm{x}=\text { Economic } \\
\text { Tb: } \mathrm{x}=\text { Mass }\end{array}$ & $\begin{array}{l}\text { Te: } 2007 \\
\text { Tb: N/A }\end{array}$ & 127 & 199 \\
\hline This study: $\mathbf{x} \_$year, extreme high & $\begin{array}{l}\text { Te: } \mathrm{x}=\text { Mass } \\
\text { Tb: } \mathrm{x}=\text { Economic }\end{array}$ & $\begin{array}{l}\text { Te: } 2013 \\
\text { Tb: } 2012\end{array}$ & 825 & 7902 \\
\hline
\end{tabular}

* REE case study: Sm-Gd-Eu: 2002; Nd, Pr, La, Ce: 2004-2006 average [73]

** Depending upon geographic assumption: Canadian or rest of the world regional perspective.

After determining a need for more modeling detail than can be provided from literature values, the next step is likely to head to an LCA modeling software resource, like Simapro or $\mathrm{GaBi}$. Simapro, for example, comes preloaded with several LCI databases, such as Agrifootprint, which focuses on agricultural products and processes, ELCD, which focuses on European data, USLCI, which focuses on US data, and ecoinvent, which represents a broad 
variety of sectors and regional data. While the unit processes available in these databases can serve as helpful starting points, it is not advisable to utilize these processes blindly without consideration for the allocation methods or assumptions (temporal, geographic, or otherwise). As demonstrated in the presented case studies, these assumptions can lead to highly variable results. The concern is the variation could potentially lead to inappropriate decision making.

This is particularly true for many minor and joint product metals used in advanced solar technology, where if they even exist, stock unit processes typically handle joint production inappropriately. Terbium represents a scenario where unit process did not exist before we modeled it. Tellurium represented a scenario where joint production modeling required improvement. Specifically, the ecoinvent database often utilizes a cutoff method, which separates the upstream carrier ore extraction and processing from the joint product extraction and processing. Cutoff would be an appropriate method if the joint products were instead wastes of no market value, but since they are not they must be treated as multifunctional processes. In best case scenario, there will be fragment processes representing each end of the cutoff, which can be manually connected. This was the case for tellurium, where copper refining is modeled to produce a waste anode slime, and then a separate anode slime processing block is available, but its input anode slime does not ever connect back to copper joint production. In more challenging scenarios, like the rare earth model, iron mining proxy processes had to be combined with existing fragment of rare earth oxide concentrate production, requiring a greater amount of additional modeling of energy and input/output estimation.

Once it is determined that independent modeling is required for a given system, whether basing the unit processes off existing database modules or starting from scratch two practices are recommended. This first is when joint production scenarios are encountered, choose to model the process as a multi-output module rather than embedding allocated inputs and outputs into two separate modules, if this is possible in your modeling software. In single output allocated modules, the allocation factors are buried within the stagnant input and output values. However, with multi-output processes, the allocation factor is held separate from the pre-allocated flows and made readily available to the practitioner. This allows for greater transparency in modeling, and it also provides valuable accessibility to create multiple allocation scenarios and test the limits of data assumptions, ultimately assessing the variability of the end results.

Finally, if a more accurate representation is known for certain modeling processes from expert study or first-hand experience, incorporate the most realistic process data into the system model. In many cases this can include improved yields. In other cases, like the tellurium case study presented in this study, this included use of alternate methods of reference flow estimation for based on more complete system modeling knowledge. For solar LCA, this tip will most likely add value when modeling processes regarding solar material growth or processing. However, it is valuable to add these contributions at every level where there is knowledge with greater specificity. In the case of this paper, the data contribution comes from expertise in supply-chain modeling of raw material inputs.

\subsection{Managing allocation variation: method selection}

As suspected, the case studies confirmed that choice of allocation method can dramatically change LCA results. This was shown to be especially true for the more minor joint products. For example, choosing mass allocation over a typical economic allocation (baseline scenario) resulted in a 5-fold increase for tellurium CED estimates and a 26-fold decrease in 
terbium CED estimates. However, technically speaking there is no "correct" method of allocation. There are justifications, which may be better or worse for a particular application. According to Weidema \& Norris "what has been missing, is a unifying theory that can explain what allocation key is justifiable in each specific situation," [33]. Research in the area of allocation remains fragmented, trying to identify methods with "better" justifications or describe scenarios in which already established methods are better justified; however, at its core, allocation is just a work around for an impossible problem. The issue is when the cause is not obvious, and a method is chosen arbitrarily or by convention, it is often not clear whether one method overestimates impacts or the other underestimates them even for the same process. This is troubling because when different people can calculate the same result in different ways and get fundamentally different answers, there is risk of unethical reporting and use of results to mislead decision making to suit the practitioner's purposes. For example, if trying to demonstrate environmental advantage of a novel solar material over a competing one, choice of allocation method and temporally-specific input data can be used to skew results in your favor. This best practice emphasizes the importance of these specific issues (allocation and related temporal data assumptions) as part of the more general transparent reporting guidelines for solar PV LCA [75].

Earlier in this study, it was thought that the nature of the joint production process, i.e. coproduction versus byproduction, might offer helpful insight into the appropriate choice of allocation method. However, this distinction becomes less clear in practice. First, not all systems are one or the other; there can be systems with both coproducts and byproducts, depending how they are defined. Additionally, when breaking down production of a material that is referred to broadly as a byproduct, such as tellurium, or a coproduct, such as rare earths, to the individual process level, the joint product may not yield directly from the same process as its carrier metal. For example, to produce tellurium copper ore is mined, refined, then anode slime is processed and tellurium is refined. The process for mining of copper ore yields copper concentrates and molybdenum concentrates. Refining of copper concentrates yields pure copper cathode and anode slime. Anode slime processing yields silver, selenium, and a copper telluride precipitate. Copper telluride refining yields only refined tellurium; there are no byproducts or coproducts. In brief, despite being broadly referred to as a byproduct of copper, at no point in the individually modeled processes described above is pure tellurium ever yielded from the same process that yields pure copper. Therefore, even though tellurium behaves as a system level byproduct, i.e. no more or less copper ore would be mined to recover more tellurium, at the process level relevant for modeling LCA tellurium and copper are not coproducts and its joint production form cannot be used as a basis for allocation decisions directly in LCA. However, at its core and in reality beyond LCA modeling, this distinction speaks to economic drivers of the production processes and has potential in this space barring further analysis and investigation.

In lieu of a proposing a better way to determine appropriate allocation strategies, it is recommended to always report results from use of at least two allocation methods, i.e. mass and economic or a more causally justifiable method, and to use these scenarios as boundary values for the result in decision making. Although it may be frustrating to work with a range rather than a single value, it will encourage decision makers to design a solution or identify conditions where the entire result range can be encompassed in a safe decision zone. Even if this complete agreement scenario cannot be reached, using a range can give an idea of what chances you have of being right. This can be used to identify conditions and tipping points for success that may lead to more nuanced decision making. 


\subsection{Managing allocation variation: temporal data selection}

A key result of this paper is the analysis of price variability on LCA results for price volatile joint product materials. In the case of tellurium, despite large price variations for the pure material, counter-influencing price trends among coproducts created small sensitivity of overall result, assuming consistent year data was used. However, in the rare earth example, terbium CED results could be changed by up to $45 \%$ in either direction depending on the year selected between the period of 2006 and 2014. Clearly, for certain joint product materials, particularly those with dramatic price trends even under allocation adjustment (Fig 9), the time period assumed can affect results dramatically as well. This effect was understated in previous analyses $[24,32]$. However, the case study results demonstrate that it is crucial when modeling joint production processes to consider historic price volatility and account for time value of money.

Traditionally, it has been thought that averaging could effectively erase this variability and lead to more time-stable results. However, solely relying on averages can be problematic for a few reasons. One is the demonstrated challenge that selecting an averaging period can appreciably change results. For example, even assuming a somewhat recent price averaging period of 2006 - 2010 rather than 2010 - 2014 for the REE LCA resulted in a 25\% decrease in terbium CED estimation. Capturing a reasonable range of extremes can be helpful to ensure the full range of results is captured as well.

A simple way to approach this challenge is to collect historic price data from resources, such as USGS, identify period highs and lows, and select those years to extend the bounds of the economic allocation scenario results. For tellurium, the extreme lower bound of $127 \mathrm{MJ} / \mathrm{kg}$ is found via single year data point from 2007 under economic allocation, and the extreme upper bound of $825 \mathrm{MJ} / \mathrm{kg}$ is found via single year data point from 2013 under mass allocation. For terbium, the extreme lower bound of $199 \mathrm{MJ} / \mathrm{kg}$ is found via mass allocation, and the extreme upper bound of $7902 \mathrm{MJ} / \mathrm{kg}$ is found via single year data point from 2012 under economic allocation (Table 3).

\section{Conclusions, Broader Impacts \& Future Work}

LCA is one of the best tools decision makers have to objectively assess environmental impacts and make decisions based on this information to manage them. Whether at the firm level or for broader policy development, it is crucial that the data used to make these decisions is as realistically representative as possible for it to be reliable. This work has reinforced how allocation decisions have the ability to dramatically affect results, particularly for materials that represent valuable but price volatile minor outputs of joint production processes, like tellurium and terbium. As such, decisions informed by LCA results are at risk of being affected and need to be robust to methodological and inherent data variability. The results of these case studies should bring greater awareness to the unique sources of variation in modeling LCA for these materials, i.e. price volatility, other time sensitive data, and allocation decisions. The best practices prescribed in this work offer several practical methods, including use of bounding techniques for allocation assumptions, to avoid misuse of LCA results and provide more nuanced and reliable basis for decision making. The two case studies reveal factors that can help predict behavior of systems like them depending upon price trends of coproducts. Notably, the results 
reveal how certain joint products can be affected differently by the same modeling choices, i.e. tellurium CED was greater by mass allocation than economic, whereas the reverse was true for terbium, due to differences in a material's upstream history.

Despite demonstrating a large impact of allocation and temporal modeling decisions on the environmental impact assessment of jointly produced solar raw materials, tellurium and terbium, these materials only constitute a small portion of the ultimate PV modules and larger installed systems. Terbium containing PV are still in development and have not been evaluated using LCA yet. However, studies of CdTe PV environmental impact $[47,56,75,78,79]$ tend to show that the tellurium-containing semiconductor material is not a major contributor to panel or system environmental impacts. Using the results of the present analysis, however, tellurium alone can be shown to contribute between 30 and $74 \%$ of the embodied energy attributable to the thin film CdTe layer material depending upon choice of allocation factor and temporal scope of data. Further, it is difficult to extrapolate the full implications at the product level without extending the methodology to other relevant system inputs, like cadmium for CdTe PV, which is a joint product of zinc and lead refining and may be subject to similar variability.

Even if variability in environmental impact determination of raw materials are not significant enough to affect PV product-level LCA results, it can still affect signals of importance to global market actors that may have serious implications for solar manufacturers' supply chains. For example, environmental impact at the raw materials level has been increasingly incorporated into assessments of materials criticality [35,37,68,80-88]. Criticality is a measure of supply-chain risk of growing interest to national organizations, like the US DOE [36,89] and DLA [90], who take strategic actions in response to perceived risk. LCA is commonly used for quantification of environmental metrics in studies that include them [68,77,81-88], creating interrelated challenges. For example, it can influence supply risk because larger environmental impact of production can lead to greater mining regulations, which can shut down marginal producers as was observed for indium in China post-2009 regulations on nonferrous mining [91]. Additionally, toxicity scores can affect substitutability of a critical material, making products more or less dependent upon the original material and affecting its vulnerability to supply disruption. Future work is needed to understand how and to what degree variabilities, like those demonstrated in this paper, which affect LCA of joint product materials can trickle back in and affect criticality results. Just as LCA can be used to inform decision making regarding environmental impact, criticality assessments can be used to inform decision making regarding supply chain security. Therefore, the same principles apply regarding their need for reliability and robustness to inherent variability. For example, criticality designation can motivate public policy action, such as stockpiling of critical materials; however, as was observed in the cobalt crisis of the 1970s, stockpiling can exacerbate supply-chain disruptions by driving up prices [92], so it is important to get the decision right.

Generally speaking, while tools like LCA exist that enable us to evaluate potentially beneficial strategies for byproduct critical materials, such as recycling, decisions and assumptions within LCA can affect whether or not we consider a strategy effective, e.g. energy savings as determined by CED of primary versus secondary material. In addition to allocation as a source of variability, future studies should direct attention to other sources of variation, including geographic factors such as ore grade, yield, energy mix, transportation assumptions, to understand how LCA uncertainties propagate differently through to decision metrics aimed at, for example, reducing environmental and/or broader criticality risk. Additionally, other 
indicators could be useful to look at for informing risk mitigation. For instance, breaking down results to look at CED from each unit process would help to target energy hotspots in these material production systems. This also has interesting implications for allocation analysis at the process level. If for instance, mining is found to contribute the greatest degree to impact, there is incentive to invest into extraction technologies. Similarly, if refining is the issue, then perhaps reduction of refined material use per product, or dematerialization, by manufacturers is the answer. Other potential indicators include GHG emissions, which can help education based campaigns, such as carbon footprint labeling for products, and resource depletion, which perhaps could inspire a similar campaign for critical material usage in products. Together, this greater systems modeling of environmental impact for joint product materials can help to enable a sustainable energy future, of which solar PV will undoubtedly be a large part.

\section{Acknowledgements}

This work has been supported by the National Science Foundation (NSF) through awards CBET \#1454166 and CBET \#1438280. The authors would also like to acknowledge the Golisano Institute for Sustainability at Rochester Institute of Technology (RIT) for continued financial support for student and faculty authors as well as access to facilities and scholarly resources, including Simapro 8 and the ecoinvent database.

\section{References}

[1] F.L. Reinhardt, Down to Earth: Applying Business Principles to Environmental Management, Harvard Business School Press, 2000. https://books.google.com/books?id=daMRuzniSyIC.

[2] N. Jungbluth, R. Frischknecht, Cumulative energy demand, in: R. Hischier, B. Weidema (Eds.), Implement. Life Cycle Impact Assess. Methods, v 2.2, St. Gallen, 2010: pp. 33-40. https://www.ecoinvent.org/files/201007_hischier_weidema_implementation_of_lcia_meth ods.pdf.

[3] M. Goe, G. Gaustad, Strengthening the case for recycling photovoltaics: An energy payback analysis, Appl. Energy. 120 (2014) 41-48. doi:http://dx.doi.org/10.1016/j.apenergy.2014.01.036.

[4] B.A. Andersson, C. Azar, J. Holmberg, S. Karlsson, Material constraints for thin-film solar cells, Energy. 23 (1998) 407-411.

[5] B.A. Andersson, Materials availability for large-scale thin-film photovoltaics, Prog. Photovoltaics Res. Appl. 8 (2000) 61-76.

[6] V. Fthenakis, Sustainability of photovoltaics: The case for thin-film solar cells, Renew. Sustain. Energy Rev. 13 (2009) 2746-2750. doi:10.1016/j.rser.2009.05.001.

[7] C. Wadia, A.P. Alivisatos, D.M. Kammen, Materials availability expands the opportunity for large-scale photovoltaics deployment, Environ. Sci. Technol. 43 (2009) 2072-2077.

[8] D.I. Bleiwas, Byproduct Mineral Commodities Used for the Production of Photovoltaic Cells, US Department of the Interior, US Geological Survey, 2010. http://pubs.usgs.gov/circ/1365/Circ1365.pdf.

[9] C. Candelise, J.F. Speirs, R.J.K. Gross, Materials availability for thin film (TF) PV technologies development: A real concern?, Renew. Sustain. Energy Rev. 15 (2011) 4972-4981. doi:10.1016/j.rser.2011.06.012. 
[10] C. Candelise, M. Winskel, R. Gross, Implications for CdTe and CIGS technologies production costs of indium and tellurium scarcity, Prog. Photovoltaics Res. Appl. 20 (2012) 816-831. doi:10.1002/pip.2216.

[11] M.L. Bustamante, G. Gaustad, Challenges in assessment of clean energy supply-chains based on byproduct minerals: A case study of tellurium use in thin film photovoltaics, Appl. Energy. 123 (2014) 397-414. doi:10.1016/j.apenergy.2014.01.065.

[12] N.T. Nassar, T.E. Graedel, E.M. Harper, By-product metals are technologically essential but have problematic supply, Sci. Adv. 1 (2015). doi:10.1126/sciadv.1400180.

[13] J. Guinée, Handbook on Life Cycle Assessment: Operational Guide to the ISO Standards, Springer Netherlands, 2006. https://books.google.com/books?id=SznhBwAAQBAJ.

[14] M.A. Curran, Co-product and input allocation approaches for creating life cycle inventory data: a literature review, Int. J. Life Cycle Assess. 12 (2007) 65-78.

[15] A. Petrick, H.J. Bennett, K.E. Starch, R.C. Weisner, The Economics of Byproduct Metals (In Two Parts), 1. Copper System, (1973) 105. http://babel.hathitrust.org/cgi/pt?id=mdp.39015078470377.

[16] G.A. Campbell, The role of co-products in stabilizing the metal mining industry, Resour. Policy. 11 (1985) 267-274. http://www.sciencedirect.com/science/article/pii/0301420785900443.

[17] D.B. Brooks, Supply and competition in minor metals, Johns Hopkins University Press, 1965.

[18] M.D. Kempe, T. Moricone, M. Kilkenny, Effects of cerium removal from glass on photovoltaic module performance and stability, in: SPIE Sol. Energy+ Technol., International Society for Optics and Photonics, 2009: p. 74120Q-74120Q-12.

[19] B.S. Xakalashe, M. Tangstad, Silicon processing: from quartz to crystalline silicon solar cells, Chem. Technol. (2012) 32-37. http://www.pyro.co.za/Mintek/Files/2012Xakalashe.pdf.

[20] M. Finkbeiner, A. Inaba, R. Tan, K. Christiansen, H.-J. Klüppel, The New International Standards for Life Cycle Assessment: ISO 14040 and ISO 14044, Int. J. Life Cycle Assess. 11 (2006) 80-85. doi:10.1065/lca2006.02.002.

[21] L. Luo, E. van der Voet, G. Huppes, H. Udo de Haes, Allocation issues in LCA methodology: a case study of corn stover-based fuel ethanol, Int. J. Life Cycle Assess. 14 (2009) 529-539. doi:10.1007/s11367-009-0112-6.

[22] S. Morais, A.A. Martins, T.M. Mata, Comparison of allocation approaches in soybean biodiesel life cycle assessment, J. Energy Inst. 83 (2010) 48-55.

doi:doi:10.1179/014426010X12592427712073.

[23] T. Wardenaar, T. van Ruijven, A. Beltran, K. Vad, J. Guinée, R. Heijungs, Differences between LCA for analysis and LCA for policy: a case study on the consequences of allocation choices in bio-energy policies, Int. J. Life Cycle Assess. 17 (2012) 1059-1067. doi:10.1007/s11367-012-0431-x.

[24] A. Stamp, H.-J. Althaus, P.A. Wäger, Limitations of applying life cycle assessment to complex co-product systems: The case of an integrated precious metals smelter-refinery, Resour. Conserv. Recycl. 80 (2013) 85-96. doi:http://dx.doi.org/10.1016/j.resconrec.2013.09.003.

[25] G.G. Zaimes, V. Khanna, The role of allocation and coproducts in environmental evaluation of microalgal biofuels: How important?, Sustain. Energy Technol. 
Assessments. 7 (2014) 247-256. doi:http://dx.doi.org/10.1016/j.seta.2014.01.011.

[26] B. Weidema, Avoiding Co-Product Allocation in Life-Cycle Assessment, J. Ind. Ecol. 4 (2000) 11-33. doi:10.1162/108819800300106366.

[27] B.P. Weidema, J.H. Schmidt, Avoiding Allocation in Life Cycle Assessment Revisited, J. Ind. Ecol. 14 (2010) 192-195. doi:10.1111/j.1530-9290.2010.00236.x.

[28] T. Ekvall, G. Finnveden, Allocation in ISO 14041 - a critical review, J. Clean. Prod. 9 (2001) 197-208. doi:http://dx.doi.org/10.1016/S0959-6526(00)00052-4.

[29] N.W. Ayer, P.H. Tyedmers, N.L. Pelletier, U. Sonesson, A. Scholz, Co-product allocation in life cycle assessments of seafood production systems: Review of problems and strategies, Int. J. Life Cycle Assess. 12 (2007) 480-487. doi:10.1065/lca2006.11.284.

[30] M. Classen, H.-J. Althaus, S. Blaser, G. Doka, N. Jungbluth, M. Tuchschmidt, Life Cycle Inventories of Metals, v2.1|10 ed., Swiss Centre of Life Cycle Inventories, Dubendorf, $\mathrm{CH}, 2009$.

[31] M. Bigum, L. Brogaard, T.H. Christensen, Metal recovery from high-grade WEEE: A life cycle assessment, J. Hazard. Mater. 207-208 (2012) 8-14. doi:http://dx.doi.org/10.1016/j.jhazmat.2011.10.001.

[32] P. Nuss, M.J. Eckelman, Life Cycle Assessment of Metals: A Scientific Synthesis, PLoS One. 9 (2014) e101298. doi:10.1371/journal.pone.0101298.

[33] B. Weidema, G.A. Norris, Avoiding co-product allocation in the metals sector, in: Present. ICMM Int. Work. Life Cycle Assess. Mater., 2002.

[34] M. Buchert, D. Schüler, D. Bleher, Critical metals for future sustainable technologies and their recycling potential, UNEP DTIE, 2009.

[35] European Commission, Critical raw materials for the EU, (2010) 84.

[36] D. Bauer, D. Diamond, J. Li, M. McKittrick, D. Sandalow, P. Telleen, Critical Materials Strategy, (2011) 196. http://energy.gov/sites/prod/files/DOE_CMS2011_FINAL_Full.pdf.

[37] L. Erdmann, T.E. Graedel, Criticality of Non-Fuel Minerals: A Review of Major Approaches and Analyses, Environ. Sci. Technol. 45 (2011) 7620-7630. doi:10.1021/es200563g.

[38] US Geological Survey (USGS), Mineral commodity summaries 2015, (2015). http://dx.doi.org/10.3133/70140094.

[39] H.S. Matthews, C.T. Hendrickson, D.H. Matthews, Life Cycle Assessment: Quantitative Approaches for Decisions that Matter, 2014.

[40] ecoinvent, Database Search, Ecoquery. 2015 (2015) Online ecoinvent database. https://v30.ecoquery.ecoinvent.org/Search/Index.

[41] M.A.J. Huijbregts, S. Hellweg, R. Frischknecht, H.W.M. Hendriks, K. Hungerbühler, A.J. Hendriks, Cumulative Energy Demand As Predictor for the Environmental Burden of Commodity Production, Environ. Sci. Technol. 44 (2010) 2189-2196. doi:10.1021/es902870s.

[42] S.G. Kumar, K.S.R.K. Rao, Physics and chemistry of CdTe/CdS thin film heterojunction photovoltaic devices: fundamental and critical aspects, Energy Environ. Sci. 7 (2014) 45102. doi:10.1039/C3EE41981A.

[43] First Solar, CdTe Technology | First Solar, (2015). http://www.firstsolar.com/en/Technologies-and-Capabilities/PV-Modules/First-SolarSeries-3-Black-Module/CdTe-Technology.aspx.

[44] N. Strevel, L. Trippel, M. Gloeckler, Performance characterization and superior energy 
yield of First Solar PV power plants in high-temperature conditions, Photovoltaics Int. 17 (2012) 7. http://www.firstsolar.com/PressCenter/ /media/D5A5448F53594E9BB7C3817B2F8F91B7.ashx.

[45] V. Fthenakis, H.C. Kim, M. Held, M. Raugei, J. Krones, Update of PV energy payback times and life-cycle greenhouse gas emissions, in: 24th Eur. Photovolt. Sol. Energy Conf. Exhib., 2009: pp. 21-25.

[46] M. Held, R. Ilg, Update of environmental indicators and energy payback time of CdTe PV systems in Europe, Prog. Photovoltaics Res. Appl. 19 (2011) 614-626. doi:10.1002/pip.1068.

[47] J. Peng, L. Lu, H. Yang, Review on life cycle assessment of energy payback and greenhouse gas emission of solar photovoltaic systems, Renew. Sustain. Energy Rev. 19 (2013) 255-274. doi:http://dx.doi.org/10.1016/j.rser.2012.11.035.

[48] V. Fthenakis, K. Zweibel, CdTe PV: Real and perceived EHS risks, Natl. Cent. Photovoltaics Sol. Progr. Rev. Meet. (2003). http://www.nrel.gov/docs/fy03osti/33561.pdf.

[49] V.M. Fthenakis, Life cycle impact analysis of cadmium in CdTe PV production, Renew. Sustain. Energy Rev. 8 (2004) 303-334. doi:http://dx.doi.org/10.1016/j.rser.2003.12.001.

[50] V.M. Fthenakis, M. Fuhrmann, J. Heiser, A. Lanzirotti, J. Fitts, W. Wang, Emissions and encapsulation of cadmium in CdTe PV modules during fires, Prog. Photovoltaics Res. Appl. 13 (2005) 713-723. doi:10.1002/pip.624.

[51] M. Bravi, M.L. Parisi, E. Tiezzi, R. Basosi, Life cycle assessment of advanced technologies for photovoltaic panels production, Int J Heat Technol. 28 (2010) 133-139.

[52] L. Jarup, M. Berglund, C.G. Elinder, G. Nordberg, M. Vahter, Health effects of cadmium exposure - a review of the literature and a risk estimate, Scand. J. Work. Environ. Health. 24 (1998) 1-51. http://www.jstor.org/stable/40967243?seq=1\#page_scan_tab_contents.

[53] L. Gerhardsson, Tellurium, in: G.F. Nordberg, B.A. Fowler, M. Nordberg (Eds.), Handb. Toxicol. Met., 4th ed., Elsevier Science, 2014: pp. 1217-1228. https://books.google.com/books?id=ZFxzAwAAQBAJ.

[54] V.M. Fthenakis, S.C. Morris, P.D. Moskowitz, D.L. Morgan, Toxicity of cadmium telluride, copper indium diselenide, and copper gallium diselenide, Prog. Photovoltaics Res. Appl. 7 (1999) 489-497. doi:10.1002/(SICI)1099-159X(199911/12)7:6<489::AIDPIP287>3.0.CO;2-N.

[55] P. Sinha, C.J. Kriegner, W.A. Schew, S.W. Kaczmar, M. Traister, D.J. Wilson, Regulatory policy governing cadmium-telluride photovoltaics: A case study contrasting life cycle management with the precautionary principle, Energy Policy. 36 (2008) 381-387. doi:10.1016/j.enpol.2007.09.017.

[56] V. Fthenakis, A. Anctil, Direct Te Mining: Resource Availability and Impact on Cumulative Energy Demand of CdTe PV Life Cycles, Photovoltaics, IEEE J. 3 (2013) 433-438. doi:10.1109/JPHOTOV.2012.2216860.

[57] M.W. George, Selenium and Tellurium, in: 2011 Miner. Yearb., 2012: pp. 65.1-65.9. http://minerals.usgs.gov/minerals/pubs/commodity/selenium/myb1-2011-selen.pdf.

[58] US Geological Survey (USGS), Tellurium Statistics, in: G. Matos, D. Buckingham, C. DiFrancesco, K. Porter, C. Berry, M. Crane, et al. (Eds.), Hist. Stat. Miner. Mater. Commod. United States, 2015. http://minerals.usgs.gov/ds/2005/140/\#tellurium.

[59] B.S. Richards, Luminescent layers for enhanced silicon solar cell performance: Down- 
conversion, Sol. Energy Mater. Sol. Cells. 90 (2006) 1189-1207.

doi:http://dx.doi.org/10.1016/j.solmat.2005.07.001.

[60] A. Shalav, B.S. Richards, M.A. Green, Luminescent layers for enhanced silicon solar cell performance: Up-conversion, Sol. Energy Mater. Sol. Cells. 91 (2007) 829-842. doi:http://dx.doi.org/10.1016/j.solmat.2007.02.007.

[61] F. Lahoz, C. Pérez-Rodríguez, S.E. Hernández, I.R. Martín, V. Lavín, U.R. RodríguezMendoza, Upconversion mechanisms in rare-earth doped glasses to improve the efficiency of silicon solar cells, Sol. Energy Mater. Sol. Cells. 95 (2011) 1671-1677. doi:http://dx.doi.org/10.1016/j.solmat.2011.01.027.

[62] C. Miao, C. Chen, Q. Dai, L. Xu, H. Song, Dysprosium, Holmium and Erbium ions doped Indium Oxide nanotubes as photoanodes for dye sensitized solar cells and improved device performance, J. Colloid Interface Sci. 440 (2015) 162-167. doi:http://dx.doi.org/10.1016/j.jcis.2014.10.055.

[63] L. Dumont, J. Cardin, P. Benzo, M. Carrada, C. Labbé, A.L. Richard, et al., SiNx:Tb3+$\mathrm{Yb3+}$, an efficient down-conversion layer compatible with a silicon solar cell process, Sol. Energy Mater. Sol. Cells. 145 (2016) 84-92. doi:http://dx.doi.org/10.1016/j.solmat.2015.09.031.

[64] H. Rodríguez-Rodríguez, M.H. Imanieh, F. Lahoz, I.R. Martín, Analysis of the upconversion process in Tm3+ doped glasses for enhancement of the photocurrent in silicon solar cells, Sol. Energy Mater. Sol. Cells. 144 (2016) 29-32. doi:http://dx.doi.org/10.1016/j.solmat.2015.08.017.

[65] A. Pandey, R.E. Kroon, V. Kumar, H.C. Swart, Photon downshifting in strong NIR emitting Er3+-Yb3+ embedded tungsten tellurite glass, J. Alloys Compd. 657 (2016) 3236. doi:http://dx.doi.org/10.1016/j.jallcom.2015.10.081.

[66] A. V Naumov, Review of the world market of rare-earth metals, Russ. J. Non-Ferrous Met. 49 (2008) 14-22. doi:10.1007/s11981-008-1004-6.

[67] British Geologic Survey, Rare Earth Elements, Commod. Profiles. (2011). http://www.bgs.ac.uk/mineralsUK/statistics/mineralProfiles.html.

[68] N.T. Nassar, X. Du, T.E. Graedel, Criticality of the Rare Earth Elements, J. Ind. Ecol. 19 (2015) 1044-1054. doi:10.1111/jiec.12237.

[69] US Geological Survey (USGS), Rare Earths; 2006-2011, Miner. Yearb. (2011).

[70] US Geological Survey (USGS), Niobium; 2006-2014, Miner. Commod. Summ. (2014).

[71] Mineral Prices, Rare Earths; 2012-2014, (2014). http://mineralprices.com/default.aspx\#rar.

[72] indexmundi, Iron Ore Monthly Price - US Dollars per Dry Metric Ton; 2006-2014, (2014). http://www.indexmundi.com/commodities/?commodity=iron-ore\&months $=120$.

[73] H.-J. Althaus, M. Chudacoff, R. Hischier, N. Jungbluth, M. Osses, A. Primas, Life cycle inventories of chemicals, Final Rep. Ecoinvent Data v2. 0 No. 8 (2007).

[74] J. Gambogi, Rare Earths, 2012 Miner. Yearb. (2012) 60.1-60.13. http://minerals.usgs.gov/minerals/pubs/commodity/rare_earths/myb1-2012-raree.pdf.

[75] R. Frischknecht, G. Heath, M. Raugei, P. Sinha, M. deWild-Scholten, Methodology Guidelines on Life Cycle Assessment of Photovoltaic Electricity, 3rd ed., International Energy Agency Photovoltaic Power Systems Programme (IEA PVPS), 2016. http://www.iea-pvps.org/index.php?id=350.

[76] G.G. Zaimes, B.J. Hubler, S. Wang, V. Khanna, Environmental Life Cycle Perspective on 
Rare Earth Oxide Production, ACS Sustain. Chem. Eng. 3 (2015) 237-244. doi:10.1021/sc500573b.

[77] M. Goe, G. Gaustad, Identifying critical materials for photovoltaics in the US: A multimetric approach, Appl. Energy. 123 (2014) 387-396.

[78] H. Kim, K. Cha, V.M. Fthenakis, P. Sinha, T. Hur, Life cycle assessment of cadmium telluride photovoltaic (CdTe PV) systems, Sol. Energy. 103 (2014) 78-88. doi:10.1016/j.solener.2014.02.008.

[79] E. Alsema, Energy requirements of thin-film solar cell modules - a review, Renew. Sustain. Energy Rev. 2 (1998) 387-415. doi:10.1016/S1364-0321(98)00019-7.

[80] European Commission, Report on Critical Raw Materials for the EU: Report of the Ad hoc Working Group on Defining Critical Raw Materials, (2014).

[81] T.E. Graedel, R. Barr, C. Chandler, T. Chase, J. Choi, L. Christoffersen, et al., Methodology of metal criticality determination, Environ. Sci. Technol. 46 (2012) 10631070.

[82] N.T. Nassar, R. Barr, M. Browning, Z. Diao, E. Friedlander, E.M. Harper, et al., Criticality of the Geological Copper Family, Environ. Sci. Technol. 46 (2012) 1071-1078. doi:10.1021/es203534z.

[83] P. Nuss, E.M. Harper, N.T. Nassar, B.K. Reck, T.E. Graedel, Criticality of Iron and Its Principal Alloying Elements, Environ. Sci. Technol. 48 (2014) 4171-4177. doi:10.1021/es405044w.

[84] E.M. Harper, G. Kavlak, L. Burmeister, M.J. Eckelman, S. Erbis, V. Sebastian Espinoza, et al., Criticality of the Geological Zinc, Tin, and Lead Family, J. Ind. Ecol. 19 (2014) 628-644. doi:10.1111/jiec.12213.

[85] S. Panousi, E.M. Harper, P. Nuss, M.J. Eckelman, A. Hakimian, T.E. Graedel, Criticality of seven specialty metals, J. Ind. Ecol. 19 (2015) 628-644. doi:10.1111/jiec.12213.

[86] E.M. Harper, Z. Diao, S. Panousi, P. Nuss, M.J. Eckelman, T.E. Graedel, The criticality of four nuclear energy metals, Resour. Conserv. Recycl. 95 (2015) 193-201. doi:http://dx.doi.org/10.1016/j.resconrec.2014.12.009.

[87] T.E. Graedel, E.M. Harper, N.T. Nassar, P. Nuss, B.K. Reck, Criticality of metals and metalloids, Proc. Natl. Acad. Sci. 112 (2015) 4257-4262. doi:10.1073/pnas.1500415112.

[88] T.E. Graedel, P. Nuss, Employing Considerations of Criticality in Product Design, JOM. 66 (2014) 2360-2366. doi:10.1007/s11837-014-1188-4.

[89] D. Bauer, D. Diamond, J. Li, D. Sandalow, P. Telleen, B. Wanner, Critical Materials Strategy, U.S. Department of Energy, Washington, D.C., 2010. http://www.osti.gov/bridge/servlets/purl/1000846-1gn61Q/.

[90] Defense Logistics Agency, Defense Logistics Agency Strategic Plan 2015 - 2022, (2014). http://www.dla.mil/Documents/Strategic Plan 2015 web.pdf.

[91] H. Duan, J. Wang, L. Liu, Q. Huang, J. Li, Rethinking China's strategic mineral policy on indium: implication for the flat screens and photovoltaic industries, Prog. Photovoltaics Res. Appl. 24 (2016) 83-93. doi:10.1002/pip.2654.

[92] E. Alonso, J. Gregory, F. Field, R. Kirchain, Material availability and the supply chain: risks, effects, and responses, Environ. Sci. Technol. 41 (2007) 6649-6656. 